\title{
NON-LINEARITIES IN THE RELATION BETWEEN THE EXCHANGE RATE AND ITS FUNDAMENTALS
}

\author{
CARlo Altavilla \\ PAUL DE GRAUWE
}

\author{
CESIFO WORKING PAPER NO. 1561 \\ CATEgORY 6: MONETARY POLICY AND INTERNATIONAL FinanCE \\ OCTOBER 2005
}

An electronic version of the paper may be downloaded

- from the SSRN website:

www.SSRN.com

- from the CESifo website:

www.CESifo-group.de 


\title{
NON-LINEARITIES IN THE RELATION BETWEEN THE EXCHANGE RATE AND ITS FUNDAMENTALS
}

\begin{abstract}
This paper investigates the relationship between the euro-dollar exchange rate and its underlying fundamentals. First, we develop a simple theoretical model in which chartists and fundamentalists interact. This model predicts the existence of different regimes, and thus nonlinearities in the link between the exchange rate and its fundamentals. Second, we account for non-linearity in the exchange rate process by adopting a Markov-switching vector error correction model (MSVECM). Finally, the paper investigates the out-of-sample forecast performance of three competing models of exchange rate determination. The results suggest the presence of nonlinear mean reversion in the nominal exchange rate process. The implications are that different sets of macroeconomic fundamentals act as driving forces of the exchange rates during different time periods. More interestingly, the nonlinear specification significantly improves the forecast accuracy during periods when the deviation between exchange rate and fundamentals is large. Conversely, when the exchange rate is close to its equilibrium value it tends to be better approximated by a naïve random walk.
\end{abstract}

JEL Code: C32, F31.

Keywords: non-linearity, Markov-switching model, fundamentals.

\author{
Carlo Altavilla \\ University of Naples "Parthenope" \\ Via Medina, 40 \\ 80133 Naples \\ Italy \\ Altavilla@uniparthenope.it
}

\author{
Paul De Grauwe \\ Catholic University of Leuven \\ Naamsestraat 69 \\ 3000 Leuven \\ Belgium \\ paul.degrauwe@econ.kuleuven.ac.be
}

We thank Alessandro Balestrino, Gianni de Fraja, Bas Jacobs, Thijs van Rens, participants of the 2005 CESifo Area Conference on Public Sector Economics in Munich, the 2005 Econometric Society World Congress at UCL in London, and seminar participants in Rotterdam for useful comments and suggestions. Dur gratefully acknowledges financial support from NWO, KNAW, and VSNU through a Vernieuwingsimpuls grant. 


\section{Introduction}

One of the most pervasive pieces of econometric evidence we have about the exchange markets is that it appears to be difficult, if not impossible, to find a linear relation between the exchange rate and its underlying fundamentals that will remain stable over a sufficiently long period of time. Ever since the path breaking research of Meese and Rogoff (1983) who observed that the link between the exchange rate and its fundamentals is structurally unstable, the evidence about the unstable nature of linear econometric models of the exchange rates has continued to accumulate (see Cheung $(2005)^{1}$.

True there have been claims of empirical success in estimating linear models (see e.g. Mark(1995)), but each time the sample period was extended or when slight changes in specifications were made structural breaks in these linear models appeared (Faust, et al.(2003)). As a result, it is fair to conclude that the relation between the exchange rate and its fundamentals is most probably a non-linear one.

This insight has led to a mushrooming of studies explicitly incorporating non-linearities between the exchange rate and its fundamentals. Many of these studies utilize the Multiple Regime Smooth Transition Autoregressive model (MR-STAR) to evaluate the nonlinear relationship between the exchange rate and its fundamentals ${ }^{2}$. Introduced by van Dijk and Franses (1999), these models generalize the well-known STAR models ${ }^{3}$. Taylor and Peel (2000), for example, employ an exponential smooth transition autoregressive (ESTAR) model to analyse the non-linear relationship between the exchange rate and its fundamentals in the US, UK and Germany. The results indicate that during periods of small deviations from fundamentals the exchange rate exhibits a unit-root. In contrast, the authors detect a rapid adjustment of the exchange rate toward its underlying fundamentals when there are large deviations from the equilibrium. Using the same methodology Taylor et al. (2001) find strong support for the nonlinear representation of exchange rate deviations from PPP.

Other studies have applied Hamilton's (1989) Markov-switching model to the foreign exchange markets and found evidence of frequent shifts of

\footnotetext{
${ }^{1}$ See also Baillie and Selover (1987), McNown and Wallace (1989), and Baillie and Pecchenino (1991).

${ }^{2}$ See for example, Micheal et al. (1997); Sarno (2000); Sarantis (1999); Taylor and Peel (2000) and Baum et al. (2001).

${ }^{3}$ STAR (Smooth Transition Autoregressive) models were originally introduced by Terasvirta and Anderson (1992). Their statistical properties are studied in Luukkonen et al. (1988), Luukkonen and Terasvirta (1991), Granger and Terasvirta (1993), Eitrheim and Terasvirta (1996).
} 
regimes in the relation between the exchange rate and its fundamentals (Engel and Hamilton (1990), De Grauwe and Vansteenkiste (2001), Frommel et al. (2005)). Sarno et al. (2003) used a Markov-switching vector equilibrium correction model (MS-VECM) in order to study the dynamic relationship between the exchange rate and fundamentals in six industrialized countries using data spanning over one hundred years. Their results suggest that the speed at which exchange rate converges to the long-run fundamental equilibrium mostly depends on the nominal exchange rate regime in operation.

Thus there is increasing evidence that the relation between the exchange rate and its fundamentals has important non-linear features. These explain why linear models are not robust in long sample periods.

In this paper we analyze two issues. First we study how this empirical evidence can be reconciled with the theory. In order to do so we propose a simple exchange rate model with heterogeneous agents. This model predicts that the relation between the exchange rate and its underlying fundamentals is subject to frequent regime shifts. Second, we analyse the nature of these regime shifts empirically using evidence of the dollar/DM (euro) exchange rate.

The remainder of the paper proceeds as follows. Section 2 proposes a theoretical model that incorporates nonlinearities in the exchange rate dynamics. In Section 3 we estimate a linear vector error correction model and test for possible non-linearities in the residuals. Section 4 discusses the econometric methodology used in order to analyze the way in which monetary fundamentals affect the exchange rate depending on the state of the economy. In Section 5 we compare the out-of-sample forecast performance of three competing models of exchange rate determination. In Section 6 concluding remarks end the paper.

\section{Theoretical Framework}

The empirical evidence suggests that the relationship between the exchange rate and the fundamentals is a non-linear one, characterized by frequent changes in the regimes linking the exchange rate to the fundamentals. Traditional linear rational expectations models cannot account for this except by introducing exogenous changes in regimes, i.e. by leaving these switches unexplained.

In this section we develop a very simple exchange rate model that exhibits endogenous switches in regimes. We start by defining the fundamental exchange rate. This is the exchange rate that is consistent with equilibrium 
in the real part of the economy. In a very simple model this could be the Purchasing Power Parity-value of the exchange rate. In more elaborate models (e.g. the monetary model, or the Obstfeld-Rogoff new open economy macro model (Obstfeld and Rogoff(1996)) this fundamental exchange rate could be determined by the interaction of more variables than the price levels. Here we assume that the fundamental exchange rate, $e_{t}^{*}$, is exogenous and that it behaves like a random walk without drift. This implies:

$$
e_{t}^{*}=e_{t-1}^{*}+\varepsilon_{t}
$$

where $\varepsilon_{t}$ is a white noise error term.

We now model the way agents make forecasts about the future exchange rates. We assume that agents can use two types of simple forecasting rules. One type of forecasting rule will be called fundamentalist, and agents who use such a rule will be called fundamentalists for short. The second type of rule will be called chartist and the agents who use this rule will be labelled chartists. We will also use the term 'technical analysts' interchangeably.

The fundamentalists are assumed to know the fundamental exchange rate. They compare the present market exchange rate with the fundamental rate and they forecast the future market rate to move towards the fundamental rate. In this sense they follow a negative feedback rule. This leads us to specify the following rule for the fundamentalists:

$$
E_{f, t}\left(\Delta e_{t+1}\right)=-\psi\left(e_{t}-e_{t}^{*}\right)
$$

where $E_{f, t}$ is the forecast made in period $t$ by the fundamentalists using information up to time $t, e_{t}$ is the exchange rate in period t, $\Delta e_{t}$ is the change in the exchange rate, and $\psi>0$ measures the speed with which the fundamentalists expect the exchange rate to return to the fundamental one. This parameter is presumably related to the speed of adjustment of prices in the goods market, but we do not specify its precise link with this speed of adjustment.

The chartists are assumed to follow a positive feedback rule, i.e. they extrapolate past movements of the exchange rate into the future. We will use the simplest possible hypothesis here: we assume that chartists extrapolate only last period's exchange rate into the future. The chartists' forecast is written as:

$$
E_{c, t}\left(\Delta e_{t+1}\right)=\beta \Delta e_{t}
$$

where $E_{c, t}$ is the forecast made by the chartists using information up to time $\mathrm{t}$, and $\beta$ is the coefficient expressing the degree with which chartists 
extrapolate the past change in the exchange rate; we assume that $0<\beta<1$ to ensure dynamic stability ${ }^{4}$.

The next step in our analysis is to specify how agents evaluate the usefulness of these two forecasting rules. The general idea that we will follow is that agents use one of the two rules, compare their profitability ex post and then decide whether to keep the rule or switch to the other one.

In order to implement this idea we use a fitness criterion in the spirit of Brock and Hommes (1997), (1998) which is based on discrete choice theory ${ }^{5}$. This means that the fractions of the total population of agents using chartist and fundamentalist rules are a function of the relative (risk adjusted) profitability of these rules. We specify this procedure as follows:

$$
\begin{aligned}
w_{f, t} & =\frac{\exp \gamma \pi_{f, t}^{\prime}}{\exp \gamma \pi_{f, t}^{\prime}+\exp \gamma \pi_{c, t}^{\prime}} \\
w_{c, t} & =\frac{\exp \gamma \pi_{c, t}^{\prime}}{\exp \gamma \pi_{f, t}^{\prime}+\exp \gamma \pi_{c, t}^{\prime}}
\end{aligned}
$$

where $w_{f, t}$ and $w_{c, t}$ are the fractions of the population who use fundamentalist, respectively chartist forecasting rules. Obviously $w_{f, t}+w_{c, t}=1$. The variables $\pi_{f, t}^{\prime}$ and $\pi_{c, t}^{\prime}$ are the (risk adjusted) profits realized by the use of chartists' and fundamentalists' forecasting rule in period $t$, i.e. $\pi_{f, t}^{\prime}=$ $\pi_{f, t}-\mu \sigma_{f, t}^{2}$ and $\pi_{c, t}^{\prime}=\pi_{c, t}-\mu \sigma_{c, t}^{2}$ and $\pi_{f, t}$ and $\pi_{c, t}$ are the profits made in forecasting, while $\sigma_{f, t}^{2}$ and $\sigma_{c, t}^{2}$ are variables expressing the risks chartists and fundamentalists incur when making forecasts. As a measure of this risk we will take the forecast errors. Finally $\mu$ is the coefficient of risk aversion.

Equation (4) can now be interpreted as follows. When the risk adjusted profits of the technical traders' rule increase relative to the risk adjusted profits of the fundamentalists' rule, then the share of agents who use technical trader rules in period $t$ increases, and vice versa. The parameter $\gamma$ measures the intensity with which the technical traders and fundamentalists revise their forecasting rules. With an increasing $\gamma$ agents react strongly to the relative profitability of the rules. In the limit when $\gamma$ goes to infinity all agents choose the forecasting rule which proves to be more profitable. When $\gamma$ is equal to zero agents are insensitive to the relative profitability of

\footnotetext{
${ }^{4}$ For more information on technical analysis and chartism see James(2003).

${ }^{5}$ This specification is often applied in discrete choice models. For an application in the markets for differentiated goods, see Anderson, et al. (1992). There are other ways to specify a rule that governs the selection of forecasting strategies. One was proposed by Kirman (1993). Another one was formulated by Lux and Marchesi (1999).
} 
the rules. In the latter case the fraction of technical traders and fundamentalists is constant and equal to 0.5. Thus, $\gamma$ is a measure of inertia in the decision to switch to the more profitable rule.

We now go into the problem of defining with more precision the profits and the risk associated with it. We define the profits as the one-period earnings of investing $\$ 1$ in the foreign asset. More formally,

$$
\begin{gathered}
\pi_{i, t}=\left[e_{t}\left(1+r^{*}\right)-e_{t-1}(1+r)\right] \operatorname{sgn}\left[\left(1+r^{*}\right) E_{t-1}^{i}\left(e_{t}\right)-(1+r) e_{t-1}\right] \\
\text { where } \operatorname{sgn}[x]=\left\{\begin{array}{cc}
1 & \text { for } x>0 \\
0 & \text { for } x=0 \\
-1 & \text { for } x<0
\end{array} \text { and } i=c, f\right.
\end{gathered}
$$

Thus, when agents forecasted an increase in the exchange rate and this increase is realized, their per unit profit is equal to the observed increase in the exchange rate (corrected for the interest differential). If instead the exchange rate declines, they make a per unit loss which equals this decline (because in this case they have bought foreign assets which have declined in price).

Finally we specify the risk variables in the following way. As mentioned earlier, we define the risk associated with forecasting to be the forecast error. In the logic of the short-run memory hypothesis used in this section we assume that agents just look at last period's forecast error. Thus we have:

$$
\sigma_{i, t}^{2}=\left[E_{t-1}^{i}\left(e_{t}\right)-e_{t}\right]^{2}
$$

We now aggregate the forecasts of chartists and fundamentalists to obtain the aggregate market forecast. The market forecast of the exchange rate change can be written as a weighted average of the expectations of chartists and fundamentalists, i.e.

$$
E_{t} \Delta e_{t+1}=-w_{f, t} \psi\left(e_{t}-e_{t}^{*}\right)+w_{c, t} \beta \Delta e_{t}
$$

where $w_{f t}$ and $w_{c t}$ are defined in (4).

The realised change in the market exchange rate in period $t+1$ equals the market forecast made at time $t$ plus some white noise errors, $\epsilon_{t+1}$ occurring in period $t+1$ (i.e. the news that could not be predicted at time $t$ ). We obtain:

$$
\Delta e_{t+1}=-w_{f, t} \psi\left(e_{t}-e_{t}^{*}\right)+w_{c, t} \beta \Delta e_{t}+\epsilon_{t+1}
$$


We now have all the equations of the model, and we can start analysing its characteristics.

The non-linear structure of our model does not allow for a simple analytical solution. As a result we have to use numerical simulation methods. One drawback of this approach is that we cannot easily derive general conclusions. We will compensate for this drawback by presenting sensitivity analyses of the numerical solutions. The simulations we perform are stochastic. Stochastic shocks occur in the model because the fundamental exchange rate is driven by a random walk (see equation (1)) and because there is noise in the process determining the market exchange rate (see equation (7). We will assume that the noise process in these equations are normally distributed with mean equal to 0 , and standard deviation equal to 0.1 .

We present two examples of stochastic simulations that are quite typical for the kind of dynamics predicted by our model (see figure 1$)^{6}$. The two upper parts of figure 1 present the simulated market and fundamental exchange rates obtained in two different simulation runs, using the same parameter configurations. The two lower parts present the corresponding shares of the chartists.

The most striking features of these simulations are the following. First, it appears that the exchange rate is very often disconnected from the fundamental exchange rate. This means that the market exchange rate follows movements that are dissociated from the fundamental rate. This is especially obvious in the first simulation run (left panels), where we find that the exchange rate is disconnected from the fundamental most of the time. In the right hand panel there are many periods of disconnection, but these are less frequent. This leads to a second feature of these exchange rate movements. There appear to be two regimes. In one regime the exchange rate follows the fundamental exchange rate quite closely. These "fundamental regimes" alternate with regimes in which the fundamental does not seem to play a role in determining the exchange rate. We will call these "nonfundamental regimes". The nature of the latter can be seen in the lower panels of figure 1. Non-fundamental regimes are characterized by situations in which the chartists' weights are very close to 1 . In contrast, fundamental regimes are those during which the chartists weights are below 1 and fluctuating significantly. These two regimes appear to correspond to two types of equilibria. Thus, a fundamental regime seems to occur when the exchange rate stays within the basin of attraction of a fundamental equilib-

\footnotetext{
${ }^{6}$ In De Grauwe and Grimaldi(2005) an extensive sensitivity analysis is performed indicating that our results are robust for a wide spectrum of parameter values.
} 
rium. In such a regime the exchange rate movements stay very close to the fundamental exchange rate. Conversely, a non-fundamental regime seems to occur when the exchange rate moves within the basins of attraction around bubble equilibria.
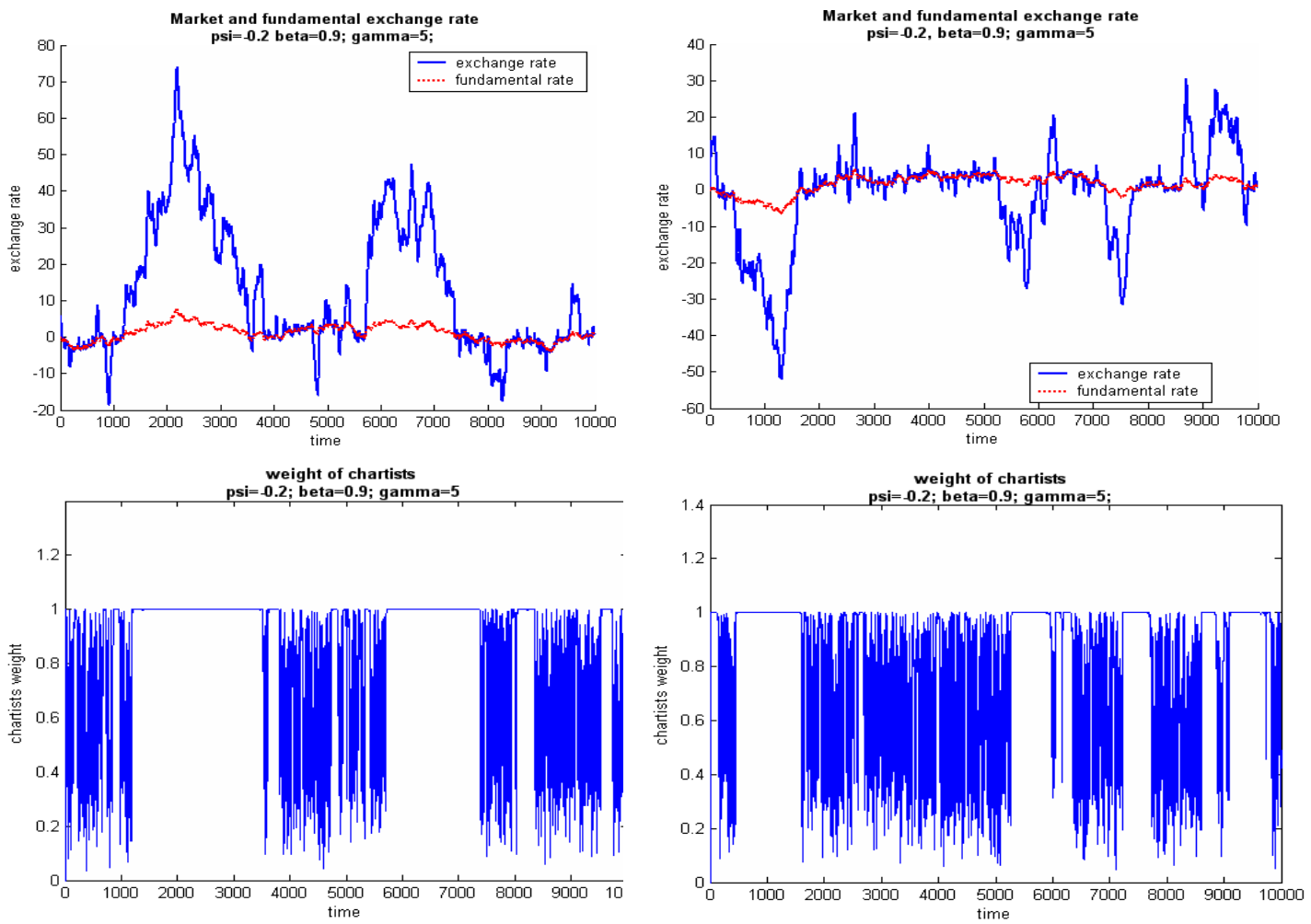

Figure 1: Stochastic Simulations of the Model

We also note from figure 1 that fundamental and non-fundamental regimes alternate in unpredictable ways. The left hand panels show a simulation during which non-fundamental regimes tend to dominate, while the right hand panels show a simulation during which fundamental regimes are more frequent. The two simulations, however, were run with exactly the same parameters. The only difference is the underlying stochastic of the fundamental exchange rate.

As mentioned earlier the numerical solutions are sensitive to the parameter values chosen. We illustrate this sensitivity by presenting simulations assuming different parameter values. Figure 2 shows the results of stochas- 
tic simulations of the model for different values of $\gamma$. It will be remembered that $\gamma$ measures the sensitivity of the switching rule to risk adjusted profits. Thus when $\gamma$ is high agents react strongly to changing profitabilities of the forecasting rules they have been using. Conversely when $\gamma$ is small they do not let their forecasting rules depend much on these relative profitabilities.

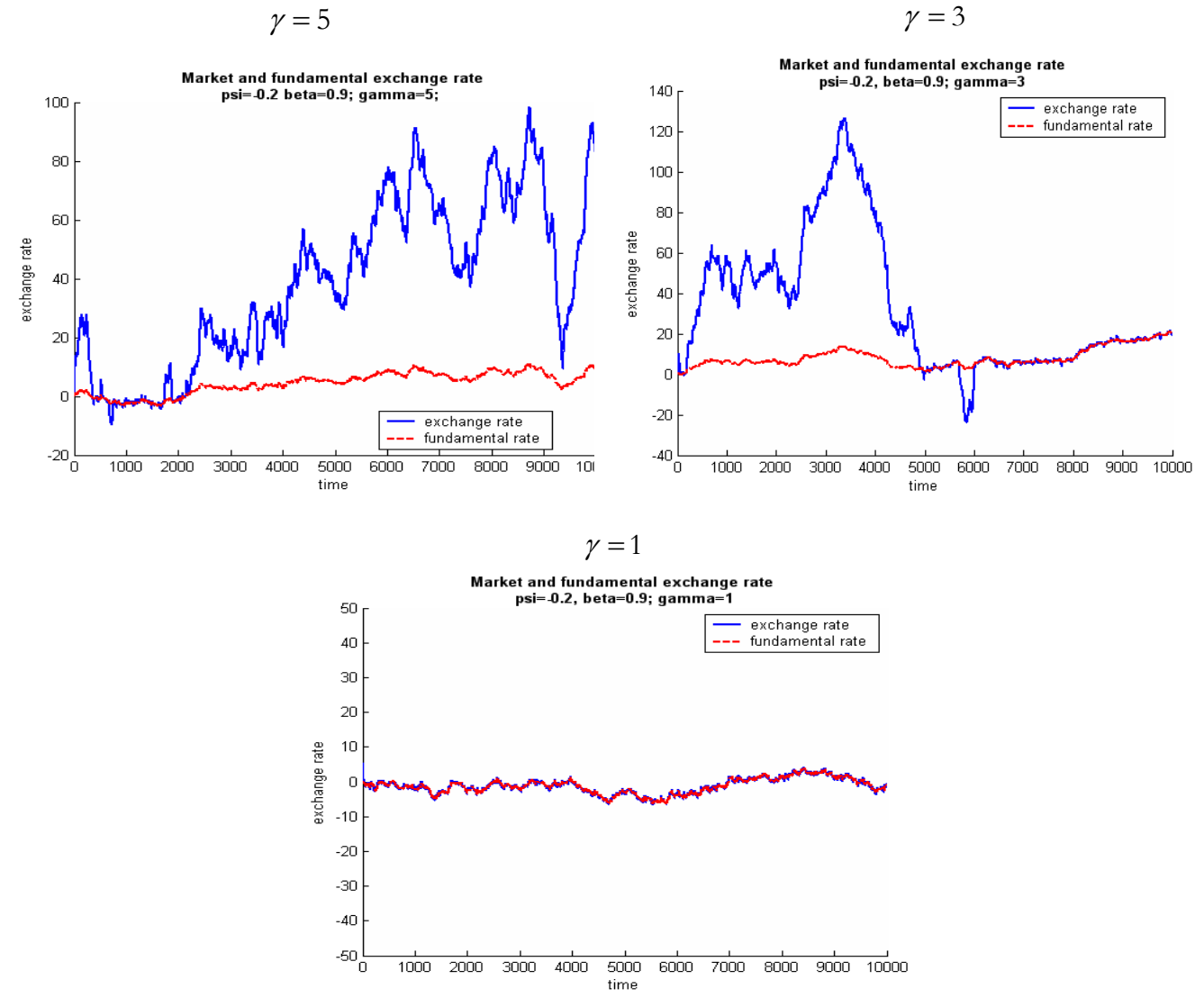

Figure 2: Model Sensitivity Analysis

The results shown in figure 2 are quite remarkable. We find that when $\gamma$ is large, the exchange rate tends to deviate strongly from the fundamental value most of the time. Thus, when $\gamma$ is high the exchange rate seems to be attracted most of the time by non-fundamental equilibria. Conversely, when agents are not very sensitive to relative profitabilities (low $\gamma$ ) the exchange rate follows the fundamental rate closely, suggesting that it is then attracted by the fundamental equilibrium most of the time. This result is 
quite surprising. It implies that when agents come closer to being rational, i.e. they always select the most profitable forecasting rule, the exchange rate deviates most strongly from the fundamental. Put differently, when agents are very rational the market exchange rate becomes a poor reflection of the underlying fundamental value.

The existence of two types of equilibria, a fundamental and a nonfundamental one, is shown in figure 3. This shows the result of a deterministic simulation of the model.

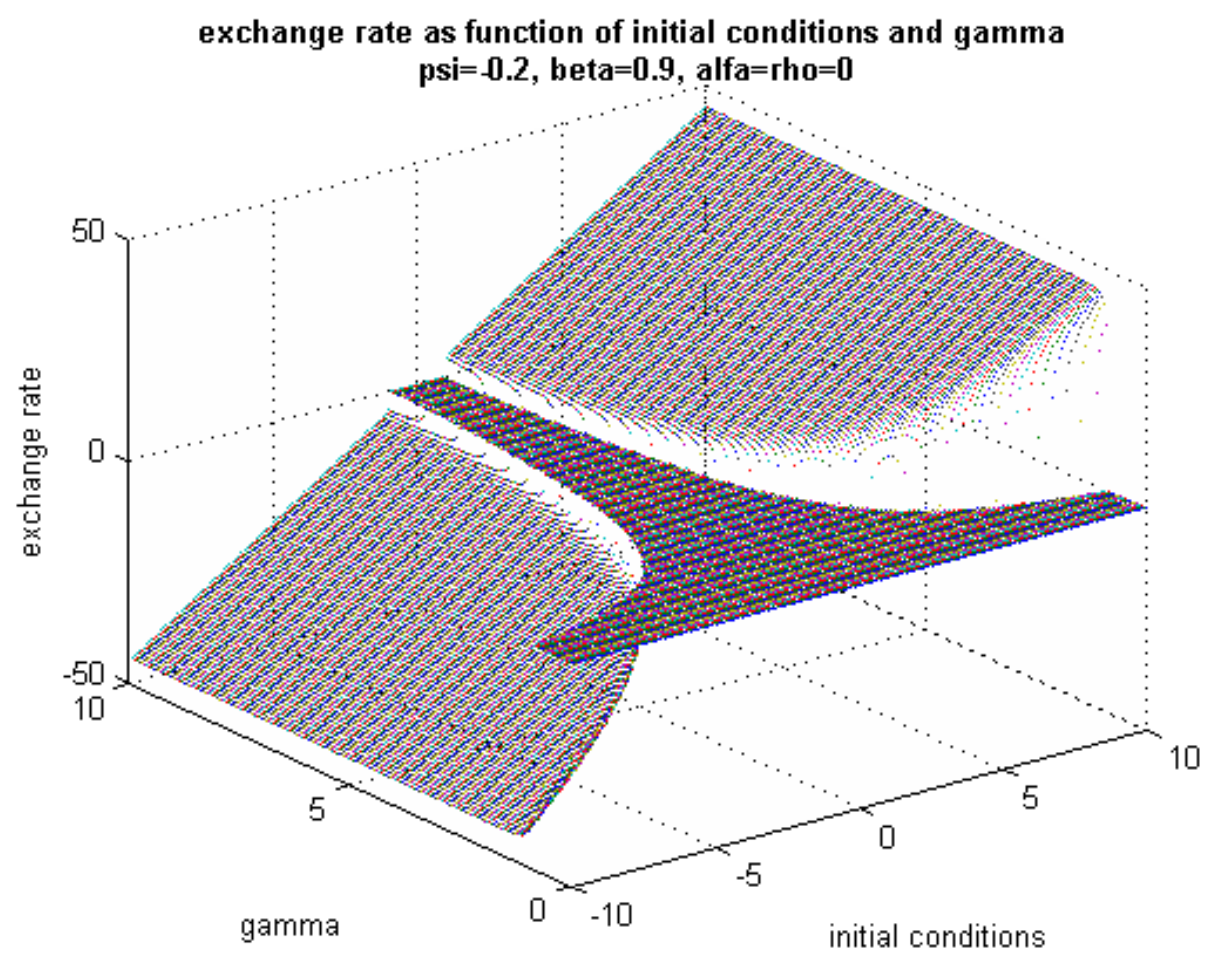

Figure 3: Deterministic Simulation of the Model

This is a simulation where the stochastics is eliminated. We then solve the model numerically for different initial conditions ( $x$-axis) and for different values of $\gamma(y \text {-axis })^{7}$. The vertical axis shows the solution of the exchange rate. This is obtained by simulating the model long enough until

\footnotetext{
${ }^{7}$ In De Grauwe and Grimaldi (2005) sensitivity analyses involving other parameters of the model are also performed.
} 
the exchange rate converges to a fixed point equilibrium. Note that we have normalized the fundamental equilibrium to be zero. As a result the vertical axis shows the equilibrium exchange rate as a deviation from the fundamental value. We find that for low values of $\gamma$ the exchange rate converges to zero, i.e. to the fundamental value. When $\gamma$ increases, however, the space of fundamental equilibria shrinks, and the space of non-fundamental equilibria increases. The latter are fixed point equilibria that permanently deviate from the fundamental equilibria. These equilibria are characterised by the fact that the share of the chartists has converged to 1, thereby eliminating the mean reversion dynamics that is exerted by the fundamentalists.

Thus the model shows that non-fundamental equilibria are possible and that the condition for their occurrence is that the chartists dominate the market. The latter is made possible by the fact that a sufficiently large initial disturbance creates a profitable chartist forecasting strategy that becomes self-fulfilling and attracts the other agents in the market. When the model is implemented in a stochastic environment it predicts that there will be frequent switches between fundamental and non-fundamental regimes. In the next sections we test this proposition empirically.

\section{$3 \quad$ Empirical testing}

The purpose of our empirical testing strategy is twofold. First, we want to find out whether there is evidence for regime switches. Second we want to explore the nature of these regimes.

In this section we perform some diagnostic tests. These aim at finding out whether there is evidence of non-linearities in the exchange rate data. In the next sections (section 4) we then turn to testing for regime switches.

In order to test for non-linearity in the exchange rate dynamics we proceed as follows. First, we estimate a linear VECM with the maximum likelihood technique. Then, we check the non-linearity of the residuals by employing a battery of standard tests. The sample period, for both the Euro Area and the United States, goes from 1979:1 to 2004:4. The data used in the empirical analysis for the USA are seasonally adjusted quarterly observations and were drawn from DataStream, which, in turn, takes the data from OECD Main Economic Indicator Database. The aggregate variables for the Euro Area, instead, come from the dataset used by Fagan et al. (2001) to construct the Area-Wide Model for the Euro Area. As the last data set ends in 1998:4 we extend the time series by adding the data reported in the ECB Monthly Bulletin. Finally, the pre-EMU exchange rate is approximated by 
a synthetic Euro/US dollar rate ${ }^{8}$.

\subsection{Linear Vector Error Correction Model}

We assume that the equilibrium value of the Euro-dollar exchange rate is determined by a set of economic fundamentals. The study concentrates on three of such fundamentals: the relative GDP, the relative inflation rate and the interest rate differential. In order to characterize the long-run dynamic adjustments, we use the following vector error correction model (VECM):

$$
\begin{gathered}
\Delta x_{t}=c+\sum_{i=1}^{k-1} \Gamma_{i} \Delta x_{t-i}+\Pi x_{t-1}+\varepsilon_{t} \\
x_{t}=\left[\begin{array}{llll}
y_{t} & \pi_{t} & i_{t} & e_{t}
\end{array}\right]^{\prime}
\end{gathered}
$$

In the above model, $y_{t}$ is the GDP differential, measured as the difference between the EU and USA real GDP; $\pi_{t}$ represents the inflation rate differential ${ }^{9} ; i_{t}$ is the short term interest rate differential, and $e_{t}$ is the euro dollar exchange rate.

The residuals from the cointegrating vector, lagged once, act as the error correction term ${ }^{10}$. This term captures the disequilibrium adjustment of each variable towards its long-run value. The parameter on the error correction terms in each individual equation indicates the speed of adjustment of this variable back to its long-run value. A significant error correction term implies long-run causality from the explanatory variables to the dependent variables. The matrix $\Pi$ is usually decomposed as:

$$
\Pi=\alpha \beta^{\prime}
$$

where $\alpha$ and $\beta$ are $n \times r$ matrices, $n$ is the number of variables and $r$ is the number of cointegrating relationships, containing the adjustment coefficient and the cointegrating vector, respectively; $\Delta$ is the first difference operator. In this form all terms are stationary, that is integrated of order zero, denoted $I(0)$.

The system can be written as:

\footnotetext{
${ }^{8}$ Details on the aggregation methodology for the Pre-EMU exchange rate time series are given in Appendix.

${ }^{9}$ The inflation rate in each country is calculated as the percentage change in the annual CPI inflation rate, i.e. $100\left(\log C P I_{t}-\log C P I_{t-4}\right)$.

${ }^{10}$ This means that the deviation of the nominal exchange rate from its fundamental value can be written as follows: $d e v_{t}=e_{t}-\left(y_{t}+\pi_{t}+i_{t}\right)$.
} 


$$
\left[\begin{array}{c}
\Delta y_{t} \\
\Delta \pi_{t} \\
\Delta i_{t} \\
\Delta e_{t}
\end{array}\right]=\Gamma(L)\left[\begin{array}{c}
\Delta y_{t-1} \\
\Delta \pi_{t-1} \\
\Delta i_{t-1} \\
\Delta e_{t-1}
\end{array}\right]+\left[\begin{array}{c}
\alpha_{11} \\
\alpha_{21} \\
\alpha_{31} \\
\alpha_{41}
\end{array}\right]\left[\begin{array}{llll}
\beta_{11} & \beta_{12} & \beta_{13} & \beta_{14}
\end{array}\right]\left[\begin{array}{c}
y_{t-1} \\
\pi_{t-1} \\
i_{t-1} \\
e_{t-1}
\end{array}\right]+\left[\begin{array}{c}
u_{t}^{y} \\
u_{t}^{\pi} \\
u_{t}^{i} \\
u_{t}^{e}
\end{array}\right]
$$

We estimated this model by using the maximum likelihood procedure developed by Johansen $(1988,1991)$.

The results are reported in table 1 .

For the inflation rate differential, the interest rate differential and for the exchange rate equations the adjustment coefficients (EC) are significantly different from zero, meaning these variables adjust to restore the long-run equilibrium. By contrast, in the GDP equation the error correction term is not significant. As $\alpha_{11}$ is not statistically different from zero, the GDP differential is said to be long-run weakly exogenous with respect to the longrun equilibrium.

The absolute value of $\alpha$ gives information about the number of quarters needed to restore the long-term equilibrium. Specifically, for values of $\alpha$ close to unity, adjustment is very fast, with the disequilibrium being totally eliminated within one quarter. For $0<\alpha<1$ the dynamic adjustment path will be monotonically convergent. 


\begin{tabular}{ccccc}
\hline & $\Delta y_{t}$ & $\Delta \pi_{t}$ & $\Delta i_{t}$ & $\Delta e_{t}$ \\
\hline \hline Constant & -0.091 & -0.002 & 0.153 & -0.220 \\
& {$[0.07]$} & {$[0.09]$} & {$[0.10]$} & {$[0.48]$} \\
$\Delta y_{t-1}$ & 0.265 & -0.216 & 0.263 & -0.576 \\
& {$[0.10]$} & {$[0.12]$} & {$[0.13]$} & {$[0.17]$} \\
$\Delta y_{t-2}$ & 0.308 & 0.130 & 0.391 & -0.454 \\
& {$[0.10]$} & {$[0.12]$} & {$[0.13]$} & {$[0.65]$} \\
$\Delta \pi_{t-1}$ & -0.098 & -0.176 & -0.054 & 0.199 \\
& {$[0.07]$} & {$[0.09]$} & {$[0.10]$} & {$[0.09]$} \\
$\Delta \pi_{t-2}$ & 0.030 & -0.380 & 0.108 & 1.105 \\
& {$[0.07]$} & {$[0.09]$} & {$[0.10]$} & {$[0.49]$} \\
$\Delta i_{t-1}$ & 0.084 & 0.101 & 0.007 & -0.431 \\
& {$[0.08]$} & {$[0.10]$} & {$[0.10]$} & {$[0.15]$} \\
$\Delta i_{t-2}$ & -0.394 & 0.067 & -0.451 & -0.035 \\
& {$[0.08]$} & {$[0.10]$} & {$[0.11]$} & {$[0.52]$} \\
$\Delta e_{t-1}$ & 0.000 & 0.017 & 0.038 & 0.322 \\
& {$[0.02]$} & {$[0.02]$} & {$[0.02]$} & {$[0.10]$} \\
$\Delta e_{t-2}$ & 0.005 & 0.039 & -0.006 & 0.081 \\
& {$[0.02]$} & {$[0.02]$} & {$[0.02]$} & {$[0.11]$} \\
$E C_{t-1}$ & -0.001 & -0.021 & -0.014 & 0.080 \\
& {$[0.005]$} & {$[0.006]$} & {$[0.007]$} & {$[0.033]$} \\
\hline
\end{tabular}

Table 1: ML estimates of the linear $\operatorname{VECM}(2)$

In our case, the estimated error-correction coefficients in the inflation and interest rate equation, i.e. the speed of adjustment to the long-run equilibrium, are quite low (0.021 and 0.014, respectively). After almost eight years, 50 percent of the disequilibrium gap created by the shock has been closed by the adjustment in inflation rate $\mathrm{e}^{11}$.

The interest rate effect on the long term equilibrium is even slower. In fact, it takes more than twelve years for the interest rate to close the 50 percent of the disequilibrium. Only the exchange rate has a short-time effect on the long-term equilibrium. According to our estimates, the exchange rate closes the 50 percent of the gap in almost two years.

The results obtained in the analysis corroborate the so-called exchange rate disconnect puzzle. This puzzle, coined by Obstfeld and Rogoff (2001), states that there is a lack of relationship between exchange rates and macroeconomic fundamentals over short to medium horizons.

\footnotetext{
${ }^{11}$ In order to obtain the number of quarters $(\tau)$ required to dissipate $x \%$ of a shock we use the following formula: $(1-\alpha)^{\tau}=(1-x \%)$, where $\alpha$ is the absolute value of the estimated speed adjustment parameter.
} 


\subsection{Testing for Non-linearity}

Next we check for non-linearity of the residuals by using three of the most popular tests. We apply the BDS, the Reset and Tsay test to the residuals of each equation in the VECM system, i.e. the output gap differential, the inflation rate differential, the interest rate differential and the exchange rate. The null hypothesis for these tests is that the residual generating process is linear. Table 2 and table 3 show the results.

\begin{tabular}{ccccccc}
\hline Dimension & \multicolumn{2}{c}{$\varepsilon=0.5 \sigma$} & \multicolumn{2}{c}{$\varepsilon=1.0 \sigma$} & \multicolumn{2}{c}{$\varepsilon \sigma$} \\
\hline & Asymptotic & Bootstrap & Asymptotic & Bootstrap & Asymptotic & Bootstrap \\
\hline \hline & & \multicolumn{5}{c}{ GDP Differential } \\
2 & $6.5 \mathrm{E}-01$ & $6.6 \mathrm{E}-01$ & $4.2 \mathrm{E}-01$ & $3.8 \mathrm{E}-01$ & $4.8 \mathrm{E}-01$ & $4.6 \mathrm{E}-01$ \\
3 & $6.0 \mathrm{E}-01$ & $6.0 \mathrm{E}-01$ & $1.9 \mathrm{E}-01$ & $2.1 \mathrm{E}-01$ & $1.7 \mathrm{E}-01$ & $2.0 \mathrm{E}-01$ \\
4 & $6.0 \mathrm{E}-02$ & $2.2 \mathrm{E}-01$ & $2.8 \mathrm{E}-02$ & $6.2 \mathrm{E}-02$ & $2.0 \mathrm{E}-02$ & $4.3 \mathrm{E}-02$ \\
5 & $4.6 \mathrm{E}-02$ & $2.6 \mathrm{E}-01$ & $1.1 \mathrm{E}-02$ & $4.4 \mathrm{E}-02$ & $2.8 \mathrm{E}-03$ & $1.3 \mathrm{E}-02$ \\
6 & $3.1 \mathrm{E}-02$ & $3.0 \mathrm{E}-01$ & $1.5 \mathrm{E}-02$ & $5.4 \mathrm{E}-02$ & $9.2 \mathrm{E}-04$ & $9.2 \mathrm{E}-03$ \\
& & & Inflation & Differential & & \\
2 & $4.4 \mathrm{E}-04$ & $1.6 \mathrm{E}-02$ & $1.5 \mathrm{E}-01$ & $1.9 \mathrm{E}-01$ & $1.8 \mathrm{E}-02$ & $5.2 \mathrm{E}-02$ \\
3 & $6.5 \mathrm{E}-03$ & $6.6 \mathrm{E}-02$ & $6.1 \mathrm{E}-02$ & $1.1 \mathrm{E}-01$ & $2.7 \mathrm{E}-02$ & $5.8 \mathrm{E}-02$ \\
4 & $2.4 \mathrm{E}-05$ & $3.0 \mathrm{E}-02$ & $1.9 \mathrm{E}-02$ & $5.2 \mathrm{E}-02$ & $2.1 \mathrm{E}-02$ & $5.3 \mathrm{E}-02$ \\
5 & $3.7 \mathrm{E}-06$ & $4.3 \mathrm{E}-02$ & $2.6 \mathrm{E}-03$ & $2.8 \mathrm{E}-02$ & $6.5 \mathrm{E}-03$ & $3.3 \mathrm{E}-02$ \\
6 & $1.3 \mathrm{E}-05$ & $9.8 \mathrm{E}-02$ & $1.0 \mathrm{E}-04$ & $1.4 \mathrm{E}-02$ & $3.8 \mathrm{E}-03$ & $2.8 \mathrm{E}-02$ \\
& & & Interest rate & Differential & & \\
2 & $3.7 \mathrm{E}-08$ & $0.0 \mathrm{E}+00$ & $8.1 \mathrm{E}-07$ & $0 \mathrm{E}+00$ & $2.3 \mathrm{E}-02$ & $7.0 \mathrm{E}-02$ \\
3 & $1.0 \mathrm{E}-15$ & $0.0 \mathrm{E}+00$ & $1.0 \mathrm{E}-11$ & $0 \mathrm{E}+00$ & $9.8 \mathrm{E}-05$ & $2.8 \mathrm{E}-03$ \\
4 & $3.0 \mathrm{E}-30$ & $0.0 \mathrm{E}+00$ & $9.2 \mathrm{E}-16$ & $0 \mathrm{E}+00$ & $3.4 \mathrm{E}-06$ & $8.0 \mathrm{E}-04$ \\
5 & $9.3 \mathrm{E}-47$ & $0.0 \mathrm{E}+00$ & $3.5 \mathrm{E}-21$ & $0 \mathrm{E}+00$ & $3.4 \mathrm{E}-08$ & $0.0 \mathrm{E}+00$ \\
6 & $1.4 \mathrm{E}-69$ & $8.0 \mathrm{E}-04$ & $2.7 \mathrm{E}-27$ & $0 \mathrm{E}+00$ & $7.7 \mathrm{E}-10$ & $0.0 \mathrm{E}+00$ \\
& & & Exchange Rate & & \\
2 & $3.0 \mathrm{E}-03$ & $2.9 \mathrm{E}-03$ & $5.3 \mathrm{E}-03$ & $6.4 \mathrm{E}-03$ & $5.9 \mathrm{E}-03$ & $7.1 \mathrm{E}-03$ \\
3 & $4.9 \mathrm{E}-04$ & $1.9 \mathrm{E}-03$ & $8.7 \mathrm{E}-03$ & $7.8 \mathrm{E}-03$ & $1.1 \mathrm{E}-02$ & $1.1 \mathrm{E}-02$ \\
4 & $6.0 \mathrm{E}-04$ & $9.7 \mathrm{E}-04$ & $2.2 \mathrm{E}-03$ & $7.1 \mathrm{E}-03$ & $1.3 \mathrm{E}-03$ & $1.4 \mathrm{E}-02$ \\
5 & $5.9 \mathrm{E}-04$ & $4.3 \mathrm{E}-04$ & $2.3 \mathrm{E}-03$ & $5.7 \mathrm{E}-03$ & $9.4 \mathrm{E}-05$ & $1.5 \mathrm{E}-02$ \\
6 & $3.2 \mathrm{E}-04$ & $1.7 \mathrm{E}-04$ & $3.3 \mathrm{E}-05$ & $4.2 \mathrm{E}-03$ & $1.2 \mathrm{E}-02$ & $1.4 \mathrm{E}-02$ \\
\hline
\end{tabular}

Table 2: BDS Test statistics

The tables report, for each equation from the VECM, the p-values under the null hypothesis that the corresponding residual is a serially i.i.d. process. Table 3 also reports the bootstrapped p-values for the BDS test statistic. All tests reject the null hypothesis of a linear generating mechanism for the residuals of the selected variables. The analysis altogether suggests the presence of non-linearities in the residuals. This evidence corroborates the decision of estimating the model in non-linear form. 


\begin{tabular}{lcc}
\hline & TSAY & RESET \\
\hline \hline GDP Differential & $3.0 \mathrm{E}-02$ & $7.0 \mathrm{E}-02$ \\
Inflation Differential & $5.9 \mathrm{E}-03$ & $6.9 \mathrm{E}-03$ \\
Interest rate Differential & $4.9 \mathrm{E}-02$ & $4.6 \mathrm{E}-02$ \\
Exchange Rate & $1.9 \mathrm{E}-02$ & $9.0 \mathrm{E}-03$ \\
\hline & & \\
Distribution & $\mathrm{F}(4,88)$ & $\mathrm{F}(2,92)$ \\
\hline
\end{tabular}

Table 3: Tsay and Reset Test statistics

\section{Modelling non-linearity: an MS -VECM}

We account for non-linearity in the selected variables by estimating a multivariate Markov-switching model. In the MS-VECM framework, the shocks to each variable in the model are allowed to influence the transition probabilities of moving from one phase to another.

The asymmetry of the effects is captured by allowing for state-dependent parameters where the latent state variable follows a Markov-switching process. The idea behind this class of models is that the parameters underlying the data generating process of the observed time series vector $x_{t}$ depend upon the unobservable regime variable $s_{t}$, which represents the probability of being in a different state of the world.

This variable $s_{t}$ is governed by an ergodic Markov chain, which is defined by the following transition probabilities:

$$
p_{i j}=\operatorname{Pr}\left(s_{t+1}=j \text { । } s_{t}=i\right) \quad \hat{P}=\left[\begin{array}{cccc}
p_{11} & p_{12} & \cdots & p_{1 m} \\
p_{21} & p_{22} & \cdots & p_{2 m} \\
\vdots & \vdots & \ddots & \vdots \\
p_{m 1} & p_{m 2} & \cdots & p_{m m}
\end{array}\right]
$$

where $p_{i j}$ is the probability that state $i$ is followed by state $j$ and $\hat{P}$ is the correspondent transition matrix. The idea is that the relation between the exchange rate and fundamentals is time-varying but constant conditional on the stochastic and unobservable regime variable.

Within this framework we can address two different questions. The first relates to the extent of currency misalignments. The second concerns the identification of the driving forces that govern the adjustment of the exchange rate and fundamentals toward their long-term equilibrium. 


\subsection{Analysing Non-linear Exchange rate Dynamics}

As in the linear case, we assume that the equilibrium value of the Eurodollar exchange rate is determined by a set of economic fundamentals, i.e. the relative GDP, the relative inflation rate and the interest rate differential.

Starting from the equilibrium exchange rate retrieved by computing a cointegrating vector we can provide a measure of the possible misalignment by comparing this equilibrium value with the actual exchange rate.

The model we estimate is a Markov-switching-intercept-autoregressiveheteroskedasticity-VECM model $(\operatorname{MSIAH}(\mathrm{m})-\operatorname{VECM}(\mathrm{p}))$ and takes the following form:

$$
\Delta x_{t}=c\left(s_{t}\right)+\sum_{i=1}^{k-1} \Gamma_{i}\left(s_{t}\right) \Delta x_{t-i}+\alpha\left(s_{t}\right) \beta^{\prime} x_{t-1}+\varepsilon_{t}
$$

where the residuals are conditionally Gaussian, $\varepsilon_{t} \mid s_{t} \sim N I D\left(0, \Sigma\left(s_{t}\right)\right)$.

This specification allows for regime shifts in the intercept ${ }^{12}$, the autoregressive coefficients, the speed of adjustment component in the cointegration matrix and the variance-covariance matrix. In our analysis, the regimedependent cointegrating vector provides information about the adjustment process through which the long-term relationship between the exchange rate and fundamentals evolves during different periods of time. Table 4 shows the maximum likelihood estimates of the above model.

The LR linearity test significantly rejects the linearity hypothesis even when considering the upper bound suggested by Davies (1987). Moreover, the AIC (12.5 vs. 14.1), and the HQ criterion (14.1 vs. 14.6) support the choice of the non-linear VECM. Table 4 allows us to evaluate the difference in the regime-dependent speed of adjustment parameters.

In the first regime, a shock to the long-run equilibrium is essentially closed by GDP differential and interest rate differential. As in the exchange rate and inflation equations the adjustment coefficient are not significant, only the GDP and the interest rate participate in the adjustment needed to restore the long-run equilibrium. More precisely, $50 \%$ of a shock to the longterm equilibrium is corrected by the output differential and by the interest

\footnotetext{
${ }^{12}$ We also estimated the model allowing for a shift in the mean of the variables. The results we obtained from the two specifications are very similar with respect to the regime classification as well as to the parameter values. As we expected, the differences between the two models mainly consist of the different pattern of the dynamic propagation of a permanent shift in regime. More precisely, in the MSIAH model, the expected growth of the variables responds to a transition from one state to another in a smoother way. See Krolzig (1997) on the peculiarity of the two models.
} 
rate differential in almost two years.

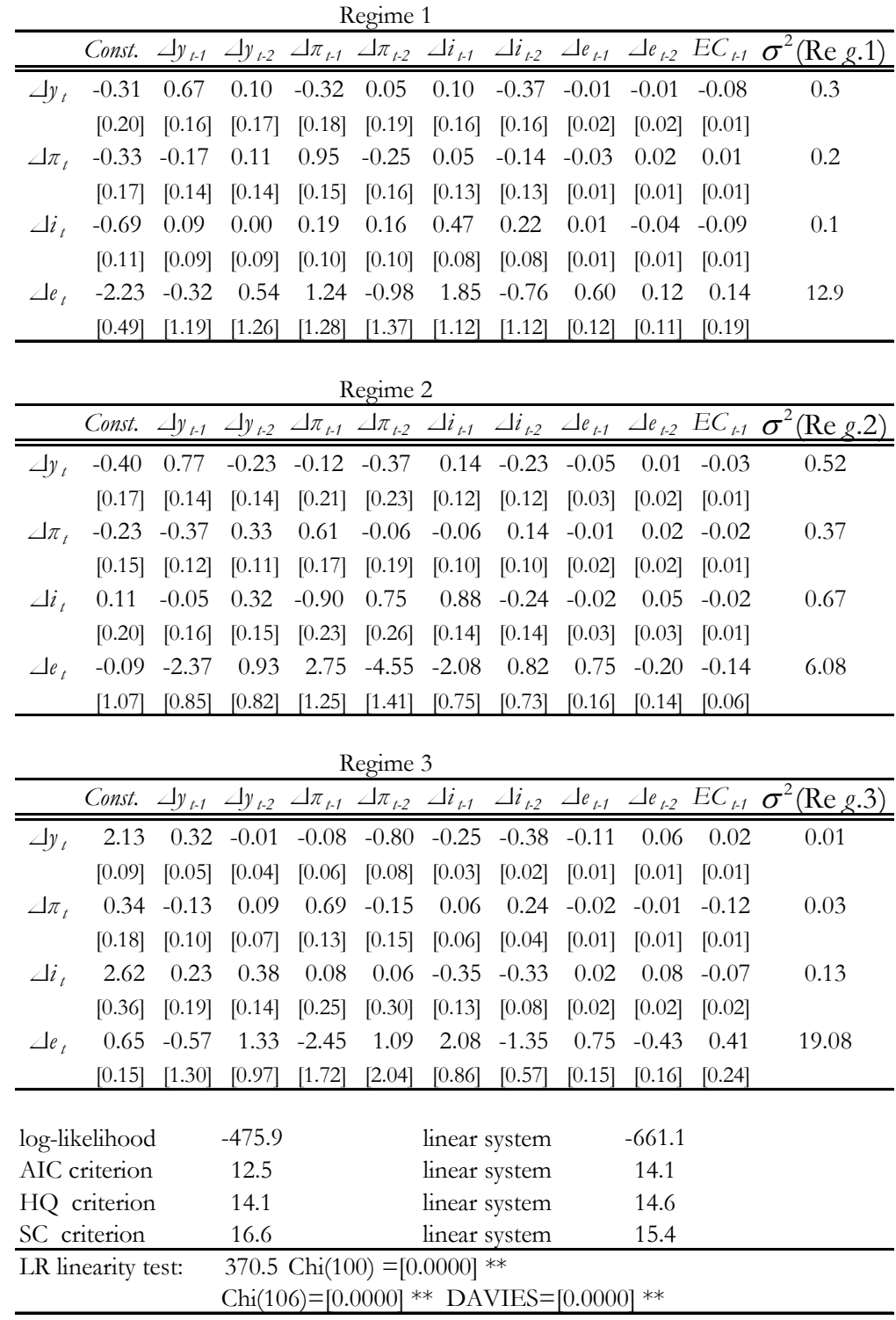

Table 4: ML estimates of the MSIAH(3)-VECM(2)

The second regime identifies periods of time where only the exchange rate significantly drive the long-term equilibrium. In fact, although the error correction coefficients are significant in all equations, only the exchange rate 
seems to bear the burden of the adjustment, with half-lives of reversion to equilibrium taking place in almost 1 year.

In the third regime, a deviation from the long-run equilibrium is corrected by changes in inflation rate differential and interest rate differential. In the second regime only these two variables act as a driving force for the exchange rate equilibrium. The proportion of the disequilibrium that is corrected by the interest rate and inflation after one year and a half is near to $40 \%$ and $60 \%$, respectively. This means that the estimated speed of adjustment for this regime is higher than that estimated by using the linear model.

Within this framework, the exchange rate is driven by fundamentals also in the short and medium term. As a consequence, the disconnect puzzle does not emerge as strongly. The evidence of episodic instability involving different sets of macroeconomic fundamentals during different time periods may explain why empirical studies have found so frequently a disconnection between macroeconomic fundamentals and the exchange rate.

Tables 5 and 6 describe the properties of the estimated regimes and the matrix of transition probability, respectively.

\begin{tabular}{lccc}
\hline & N. Obs & Prob. & Duration \\
\hline \hline Regime 1 & 35.1 & 0.40 & 10.79 \\
Regime 2 & 51.9 & 0.48 & 8.7 \\
Regime 3 & 14.0 & 0.12 & 6.57 \\
\hline
\end{tabular}

Table 5: Regime Properties

\begin{tabular}{lrrr}
\hline & Regime 1 & Regime 2 & Regime 3 \\
\hline \hline Regime 1 & 0.85 & 0.00 & 0.15 \\
Regime 2 & 0.05 & 0.90 & 0.04 \\
Regime 3 & 0.10 & 0.11 & 0.79 \\
\hline
\end{tabular}

Table 6: Matrix of Transition Probabilities

The regimes are estimated to be quite persistent. The expected duration of regimes 1 and 3 is 6.61 quarters and 4.84 quarters, respectively ${ }^{13}$. Regime 2 is expected to last for 10.16 quarters. The main characteristics of the

\footnotetext{
${ }^{13}$ The expected duration can be easily calculated from the estimated transition probabilities. The expected duration of an appreciation, for example, can be derived as follows: $\cdot \sum_{z=1}^{\infty} z p_{11}^{z-1}\left(1-p_{11}\right)=\left(1-p_{11}\right)^{-1}$.
} 
estimated regimes are summarized in Figure 4 and Table 7 . In figure 4 the periods where output and interest rate drive the long-term equilibrium (Regime 3) coincide with the periods where there has been an appreciation of the exchange rate. On the contrary, when inflation and interest rate largely influence the long-term equilibrium (Regime 1) the exchange rate depreciates. Finally, the second half of the 1980s, the early 90 s, and the years 1997-2002 are associated with the increasing importance of exchange rate in determining the long-run equilibrium.

The evidence suggests that during euro-depreciation episode (e.g. early 1980s and early 1990s), the emphasis is on differences in the rates of inflation between countries and the interest rate differentials that might have caused them. On the contrary, during euro-appreciation episodes (e.g. 8586, 93-95, 02-04), inflation rates came down and converged across countries but exchange rate movements remained large. This lead to more emphasis being placed on GDP differential and factors that affect the real economy. Finally, when exchange rate is close to its fundamental value (e.g. 99-01), non-monetary factors largely affect exchange rates. During these periods exchange rate movements do not depend on economic fundamentals but instead on self-fulfilling beliefs and expectations.

These results can be explained in the context of our theoretical model. When the exchange rate is close to the fundamental, the fundamentalists forecast little change in the exchange rate. As a result, the forecasts are dominated by chartists. Thus, movements of the exchange rate close to the fundamentals appear to be disconnected from the fundamental. In contrast, when the exchange rate is far from the fundamental, the attractive forces of the fundamental increase.

\begin{tabular}{lll}
\hline Regime 1 & Regime 2 & Regime 3 \\
\hline \hline 1985:1 - 1988:2 [0.9791] & $1979: 4-1981: 3[0.9980]$ & $1981: 4-1984: 3[0.9089]$ \\
1994:1 - 1996:4 [0.9415] & $1984: 4-1985: 3[0.9043]$ & $1991: 1-1992: 2[0.9534]$ \\
2002:2 - 2004:4 [0.9543] & $1988: 3-1990: 4[0.9636]$ & \\
& $1992: 3-1993: 4[0.9236]$ & \\
& $1997: 1-2002: 1[0.9353]$ & \\
\hline
\end{tabular}

Table 7: Regime Classification 

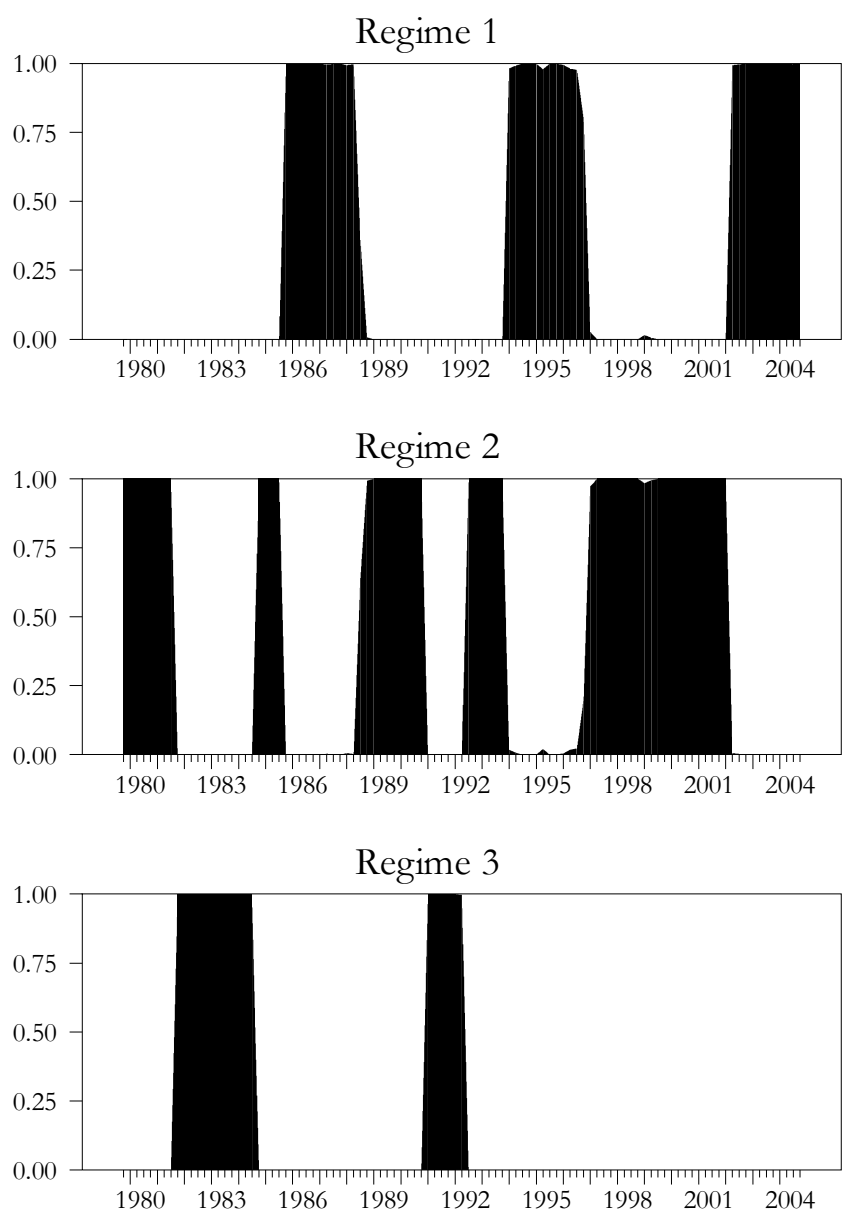

Figure 4: Smoothed Regime Probabilities

\section{Out-of-sample Forecasting Properties}

In the previous section, we argued that even if the relationship between the exchange rate and its fundamentals is found to be time-varying, it is possible to identify periods of time where the relationship becomes stable. An interesting question is then whether it is possible to improve the out-ofsample forecasting performance by using models that incorporate nonlinear mean reversion. In order to do it, we perform a standard forecast estimation and evaluation strategy. In particular, we first estimate a set of competing 
models over some periods and construct out-of-sample forecasts. Then we compare these forecasts with the actual exchange rate outcome.

The aim of this section is to test whether large deviation from fundamentals creates a tendency for exchange rate predictability to emerge. To this end, we examine evidence on how the ability of alternative models to forecast the exchange rate might change over time.

The empirical analysis is based on three alternative models which we, now, describe in detail. The first one (RW) consists of a driftless random walk model. As stressed above, the random walk remains a useful benchmark against which exchange rate models are judged. The model is as follows:

$$
e_{t}=e_{t-1}+\varepsilon_{t}
$$

The second one is the four variable vector error correction model (VECM) described in equation [8]. The last one consists of a markov switching VECM (MS-VECM).

Once each different type of model has been estimated, the question arises as to how their performance might best be compared. There are a number of different ways in which the forecast accuracy of competing models can be assessed. In this paper we use out-of-sample prediction errors and consider two statistical measures - forecast encompassing tests and directional accuracy tests.

\subsection{Forecasting Procedure}

The three models explained above are estimated on a sub-sample of the historical data. Then the out-of sample forecast of the competing models for alternative periods are evaluated. The forecast accuracy is measured by computing rolling forecasts. The estimation period goes from 1978:1 to 1989:4, while the forecast period goes from 1990:1 to 2004:4. This means that the first sequence of 1 to 4 -quarter ahead forecast is generated starting from 1990:1. Then, the starting date of the forecast period is rolled forward one period, and another sequence of forecasts is generated. This loop is repeated until we have $60 \times 1$-quarter forecasts, down to $57 \times 4$-quarter forecasts.

Figure 5 and 6 characterize four periods of the Euro-dollar history.

The four periods are 1992:1 to 1994:4, 1996:1 to 1998:4, 1998:1 to 2000:4 and 2001:4 to 2004:4. Each period is analysed in terms of the ability of the linear VECM; the MSVECM and the RW to forecast the actual exchange rate. For each period the figures show the 1- and 4-quarter ahead forecasts (the first and second column, respectively). 

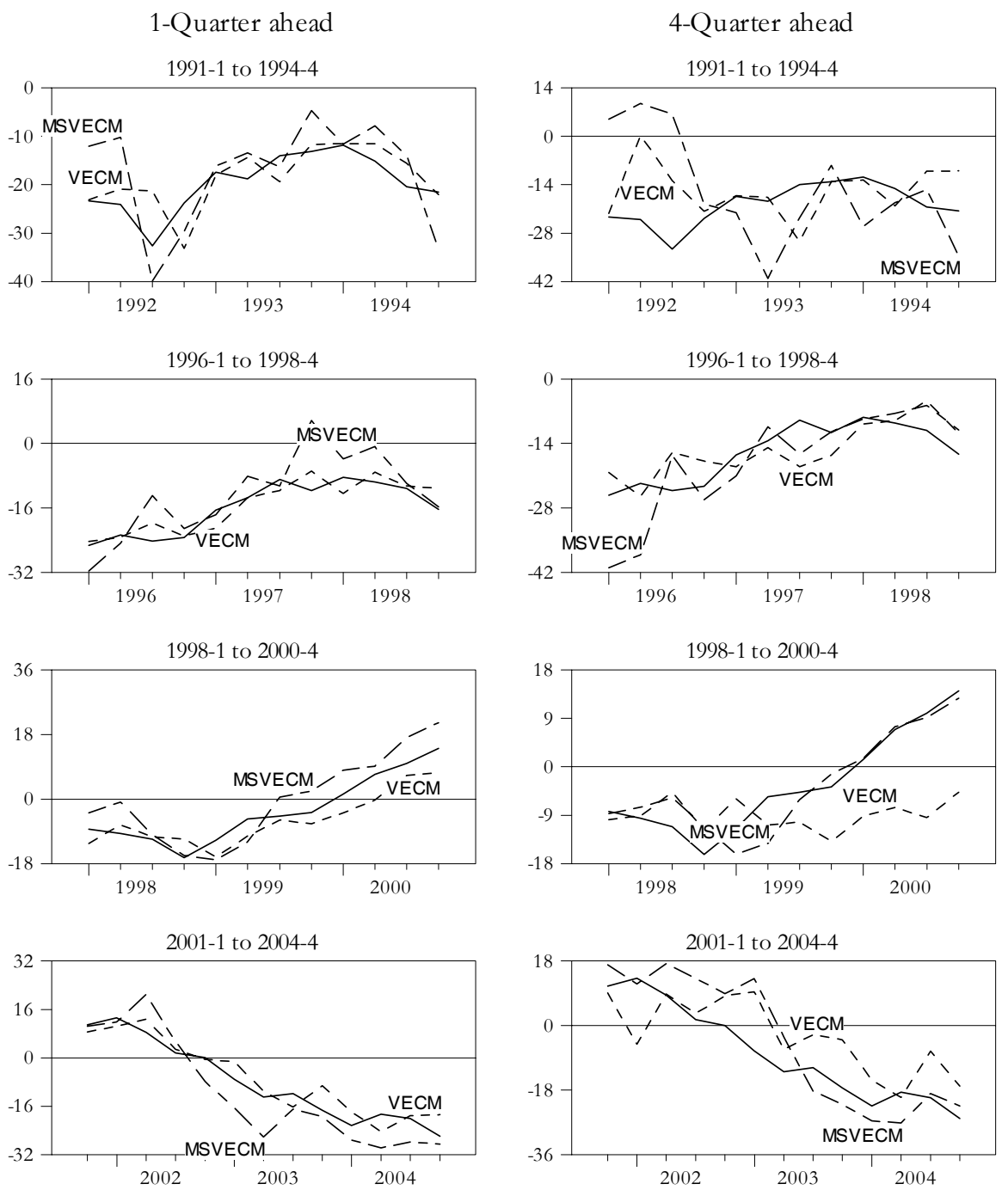

Figure 5: Out-of-sample Point Forecasts: MSVECM vs. linear VECM

Figure 5 and figure 6 provide a graphical summary of the performances of the three models described above over particular time periods in forecasting the Euro-Dollar exchange rate. Visual inspection seems to suggest that MSVECM does not consistently outperform, in terms of forecast errors, the linear VECM and the RW. In fact, the evidence emerging from figure 5 and 6 does not provided a consistent and unambiguous picture concerning the 
forecast ability of the selected models. The forecast ability of alternative models seems to vary across the sub-sample. The evidence emerging from these figures corroborates the hypothesis of having more than one states operating during the sample period.

However, in order to assess the performance of the alternative models we have to analyse the forecast accuracy through a set of statistical measure.
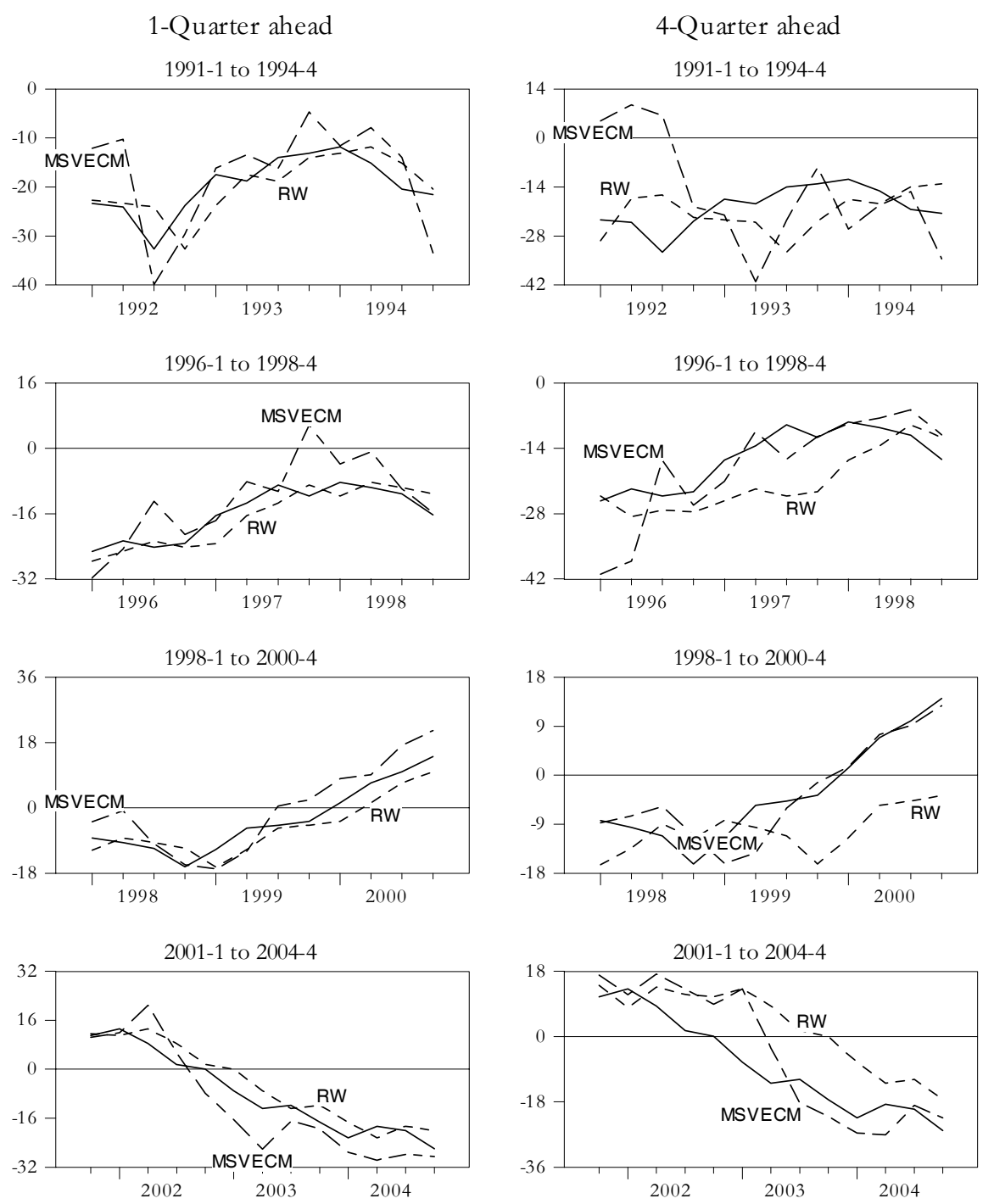

Figure 6: Out-of-sample Point Forecasts: MSVECM vs. naïve Random Walk 


\subsection{Assessing Forecast Accuracy}

We first use standard quantitative procedures involving the forecast errors. Precisely, the forecast error can be defined as: $e_{t+k}=x_{t+k}-\widehat{x}_{t+k}$, where $k \geqslant 1$ and $\widehat{x}_{t+k}$ represents the $\mathrm{k}$-step ahead forecast. Three widely used measures of forecast accuracy are the Mean Error (ME), the Mean Absolute Error (MAE) and the Root Mean Square Error (RMSE) of a model. We can calculate them as follows:

$$
M E=\frac{1}{n} \sum_{i=1}^{n} e_{t+k+i}, M A E=\frac{1}{n} \sum_{i=1}^{n}\left|e_{t+k+i}\right|, R M S E=\left(\frac{1}{n} \sum_{i=1}^{n} e_{t+k+i}^{2}\right)^{1 / 2}
$$

The comparison of forecasting performance based on these measures is summarized in Table 8.

\begin{tabular}{|c|c|c|c|c|c|c|c|c|}
\hline \multirow{2}{*}{ 1991(1) to 1994(4) } & \multicolumn{2}{|c|}{$\mathrm{ME}$} & \multicolumn{2}{|c|}{ MAE } & \multicolumn{2}{|c|}{ RMSE } & \multicolumn{2}{|c|}{ Rank } \\
\hline & 1 & 4 & 1 & 4 & 1 & 4 & 1 & 4 \\
\hline RW & 0,86 & 1,06 & 5,08 & 10,40 & 6,43 & 14,63 & 3 & 3 \\
\hline $\operatorname{VECM}(2)$ & $-0,85$ & $-1,32$ & 4,71 & 7,84 & 5,88 & 11,12 & 2 & 2 \\
\hline $\operatorname{MS}(3)-\operatorname{VECM}(2)$ & 0,61 & 1,69 & 4,04 & 7,92 & 5,33 & 9,09 & 1 & 1 \\
\hline $1996(1)$ to $1998(4)$ & \multicolumn{2}{|c|}{$\mathrm{ME}$} & \multicolumn{2}{|c|}{ MAE } & \multicolumn{2}{|c|}{ RMSE } & \multicolumn{2}{|c|}{ Rank } \\
\hline $\bar{k}$ & 1 & 4 & 1 & 4 & 1 & 4 & 1 & 4 \\
\hline RW & 0,94 & 5,18 & 2,98 & 6,51 & 3,42 & 7,66 & 2 & 3 \\
\hline $\operatorname{VECM}(2)$ & $-0,59$ & $-0,57$ & 2,56 & 4,46 & 3,18 & 5,24 & 1 & 1 \\
\hline $\operatorname{MS}(3)-\operatorname{VECM}(2)$ & $-3,34$ & 1,89 & 5,20 & 5,84 & 7,12 & 7,63 & 3 & 2 \\
\hline 1998(1) to 2000(4) & \multicolumn{2}{|c|}{$\mathrm{ME}$} & \multicolumn{2}{|c|}{ MAE } & \multicolumn{2}{|c|}{ RMSE } & \multicolumn{2}{|c|}{ Rank } \\
\hline $\bar{k}$ & 1 & 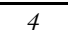 & 1 & 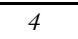 & 1 & $\overline{4} 4$ & 1 & 4 \\
\hline RW & 2,15 & 6,90 & 3,48 & 8,57 & 3,93 & 9,95 & 1 & 2 \\
\hline $\operatorname{VECM}(2)$ & 2,66 & 5,72 & 4,02 & 8,55 & 4,46 & 10,44 & 2 & 3 \\
\hline $\operatorname{MS}(3)-\operatorname{VECM}(2)$ & $-3,16$ & 0,12 & 5,13 & 2,77 & 5,68 & 3,76 & 3 & 1 \\
\hline 2001(1) to 2004(4) & \multicolumn{2}{|c|}{$\mathrm{ME}$} & \multicolumn{2}{|c|}{ MAE } & \multicolumn{2}{|c|}{ RMSE } & \multicolumn{2}{|c|}{ Rank } \\
\hline $\bar{k}$ & 1 & 4 & 1 & 4 & 1 & 4 & 1 & 4 \\
\hline RW & $-2,70$ & $-7,46$ & 4,79 & 9,98 & 5,09 & 11,54 & 2 & 3 \\
\hline VECM(2) & $-0,88$ & $-1,86$ & 4,23 & 8,72 & 5,66 & 10,17 & 3 & 2 \\
\hline $\operatorname{MS}(3)-\operatorname{VECM}(2)$ & $-2,50$ & $-3,96$ & 4,09 & 6,07 & 4,63 & 8,79 & 1 & 1 \\
\hline
\end{tabular}

Table 8: Comparing Forecast Accuracy 
The Table contains the ME, the MAE and the RMSE from five estimated models, covering two forecasting horizons: 1- and 4-step-ahead forecast (where $k=1,4$ denotes the forecast step). This table also reports the relative ranking in terms of forecast error.

The first period, occurring in the early 1990s, embraces the European monetary system crises. During these years, the actual exchange rate appears to be better approximated by the nonlinear VECM. The second period covers the mid-1990s, while the third period, ranging from the late 1990s to the early 2000s, embraces the launch of the Euro. In these years the RW forecasts appears to be much closer to the actual exchange rate. Finally, the fourth period goes from the early 2000s to the end of the sample. Contrary to the results of previous time periods, the forecast ability of the MSVECM seems to be higher than the one of the random walk.

Overall, non-linear mean-reversion models outperform random walk models when the deviation from long-term equilibrium is large.

The above measures provide a quantitative estimate of the forecasting ability of a specific model, allowing different models to be ranked, but does not provide a formal statistical indication of whether one model is significantly better than another. We also explicitly test the null hypothesis of no difference in the accuracy of the two competing forecasts by using forecast encompassing tests. In particular, we use the Diebold-Mariano (1995) forecast comparison tests.

More precisely, the accuracy of the alternative forecasts can be judged according to some specified loss function, $g($.$) . In analysing formal tests$ of the null hypothesis of equal forecast accuracy, we follow Diebold and Mariano (1995) and define the loss function as a function of the forecast errors. The loss differential is then denoted as $d_{t}=g\left(e_{1 t}\right)-g\left(e_{2 t}\right)$, where $e_{1 t}$ and $e_{2 t}$ are the forecast errors at time $t$ of the model 1 and 2 . The null hypothesis of unconditional equal forecast accuracy in this context is that the loss differential has mean 0 :

$$
H_{0}: E\left[d_{t}\right]=0
$$

According to the null hypothesis the errors associated with the two forecasts are equally costly, on average. If the null is rejected, the forecasting method that yields the smallest loss is preferred. Given a series, $\left\{d_{t}\right\}_{t=1}^{T}$, of loss differentials, the test of forecast accuracy is based on: 


$$
\bar{d}=\frac{1}{T} \sum_{t=1}^{T} d_{t}
$$

The Diebold and Mariano (1995) (DM) parametric test is a well-known procedure for testing the null hypothesis of no difference in the accuracy of two competing forecasts. It is given by:

$$
D M=\frac{d_{t}}{\sqrt{\widetilde{s}(\bar{d})}}
$$

where $\widetilde{s}$ is an estimate of the asymptotic variance of $\bar{d}$.

Table 9 reports the results of the DM test over different sub-sample for the 1- and 4-quarter ahead forecasts. The numbers in square brackets are p-values for $\mathrm{MS}(3)-\operatorname{VECM}(4)$ equal to competing model versus the MS(3)$\operatorname{VECM}(4)$ better than the alternative.

\begin{tabular}{lcccc}
\hline & $k=1$ & & $k=4$ & \\
\hline \hline & & & & \\
1991(1) to 1994(4) & & & & \\
RW & $-2,24$ & {$[0,01]$} & $-2,48$ & {$[0,01]$} \\
VECM(2) & $-2,11$ & {$[0,02]$} & $-2,47$ & {$[0,01]$} \\
& & & & \\
1996(1) to 1998(4) & & & & \\
RW & 2,22 & {$[0,99]$} & $-1,84$ & {$[0,03]$} \\
VECM(2) & 2,10 & {$[0,98]$} & $-1,87$ & {$[0,03]$} \\
& & & & \\
1998(1) to 2000(4) & & & & \\
RW & 0,24 & {$[0,59]$} & $-2,10$ & {$[0,02]$} \\
VECM(2) & 0,73 & {$[0,77]$} & $-1,49$ & {$[0,07]$} \\
& & & & \\
2001(1) to 2004(4) & & & & \\
RW & $-2,33$ & {$[0,01]$} & $-2,48$ & {$[0,01]$} \\
VECM(2) & $-1,59$ & {$[0,06]$} & $-1,92$ & {$[0,03]$} \\
\hline
\end{tabular}

Table 9: DM Forecast Comparison Tests: MSVECM vs. Competing Models

Over our forecasting sample, we find that nonlinear VECM do not consistently out-performs competing linear models. More precisely, the nonlinear specification significantly improves forecast accuracy during periods when the deviation between exchange rate and fundamentals is large (1991:11994:4 and 2001:1-2004:4). On the contrary, when the exchange rate is 
close to its equilibrium value it tends to be better approximated by a naïve random walk.

\section{Conclusions}

In this paper we investigated whether the dynamic interaction between the exchange rate and its fundamentals is time-varying. We first developed a simple theoretical model of the exchange rate in which chartists and fundamentalists interact. This model predicts that exchange rate movements will be characterized by different regimes, which we called fundamental and non-fundamental regimes. When in a fundamental regime the exchange rate stays close to the fundamental. There are also non-fundamental regimes in which the exchange rate is disconnected from the fundamentals. The existence of different regimes creates a non-linearity in the link between the exchange rate and its fundamentals.

In the empirical part of the paper we analysed the nature of these nonlinearities by specifying and estimating a Markov switching model. This model aims at identifying the driving forces that govern the adjustment of the exchange rate and fundamentals toward their long-term equilibrium. We found that the relationship between the exchange rate and its fundamentals is episodically unstable. This implies that the switching nature of the exchange rate process is inconsistent with a linear representation of the relation between the exchange rate and its fundamentals. The evidence of episodic instability involving different sets of macroeconomic fundamentals during different time periods may explain why empirical studies have found so frequently a disconnection between macroeconomic fundamentals and the exchange rate.

Finally, we examine the predictive power of various models. In out-ofsample forecasting tests, mean-reversion models (both linear and non-linear) are compared to random walks. A naïve constant change forecast remains a benchmark against which exchange rate models are judged. A set of forecast evaluation techniques were employed to judge the relative performance of three competing models of the exchange rate determination. We find that the nonlinear specification significantly improves forecast accuracy during periods when the deviation between exchange rate and fundamentals is large. Conversely, when the exchange rate is close to its equilibrium value it tends to be better approximated by a naïve random walk. 


\section{APPENDIX: A Synthetic Euro-Dollar Exchange Rate}

In the empirical analysis we investigate the relationship between the euro-dollar exchange rate and its fundamentals for the period 1979:1 - 2004:4. The length of the sample period raises the question of what variable should be used to proxy the euro exchange rate during the pre-EMU period. Some studies, like la Cour and MacDonald (2000), consider the European Currency Unit (ECU). However, the use of the ECU is not completely appropriate.

In fact, on the one hand the ECU currency basket includes countries, like Denmark and the United Kingdom, which have not introduced the new currency in 1999; on the other hand, it does not take into account countries, like Austria and Finland, which joined the EMU since 1999.

For these reasons we construct a synthetic euro-dollar exchange rate for the pre-EMU era. The value of the Euro is derived from a weighted average of the exchange rates of the EMU member countries. As Greece joined the Eurozone on 01 January 2001, the drachma is not considered in the aggregation. The weights used in the aggregation are the GDP weights (1995) at PPP exchange rates proposed by Fagan et al. (2001). The exchange rate series of the individual economies, defined as national currency per US Dollar, are taken from the International Financial Statistics (IFS) of IMF.

Figure 1A depicts the ECU/Dollar and the synthetic-Euro/Dollar. All variables are shown in levels as well as in first differences. The figure suggests that the two measures of the pre-EMU euro exchange rate do not show large discrepancies. In fact, the external value of the Euro (according to both definitions) depreciates against the US dollar during the periods 1980:31985:1, 1992:3-1994:1 and 1998:4-2001:3 (the vertical gridlines in the upper panel of figure 1A highlight these periods). On the contrary, during the second half of the eighties, the mid-nineties and the period 2001:4-2004:3 the euro appreciates against the dollar.

However, some differences might be noted concerning the time path of the two series during the ERM crises. During the early-nineties, the level of the synthetic-aggregate euro was somewhat below that of the ECU. This evidence mostly reflects the greater stability of the national exchange rates comprised in the ECU with respect to the currencies of the EMU participating economies. 

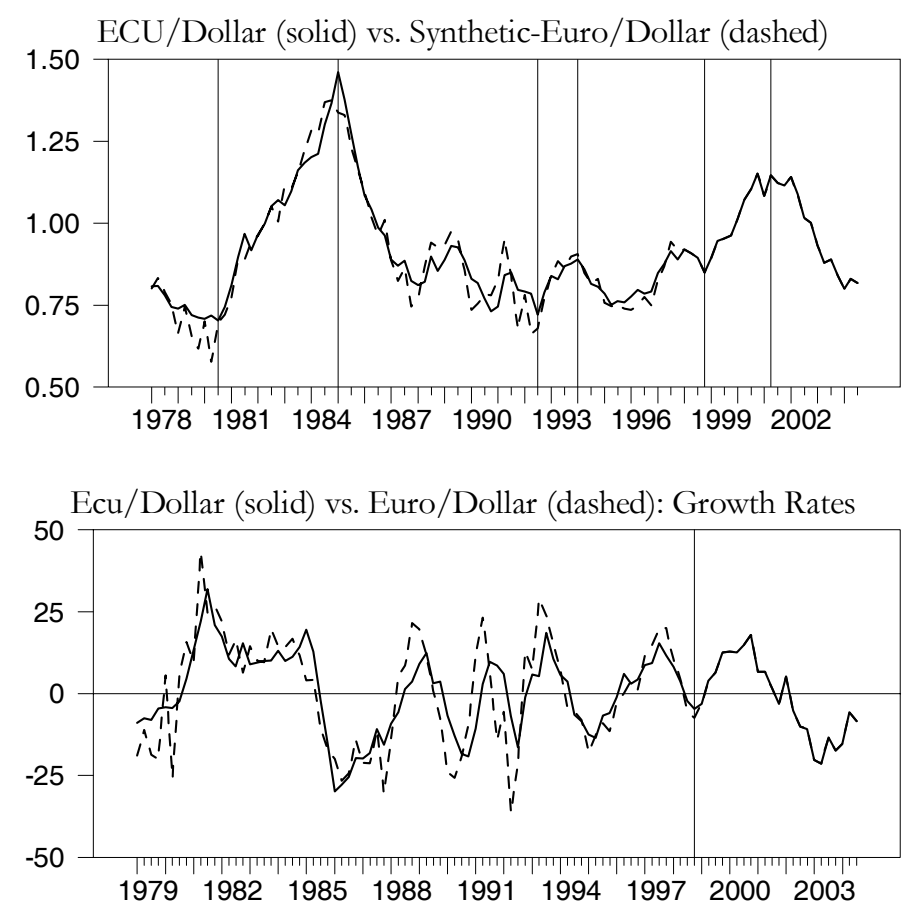

Figure 1A: The Euro/Dollar Exchange Rate 


\section{References}

[1] Anderson, S., de Palma, A., Thisse, J.-F. (1992), Discrete Choice Theory of Product Differentiation, MIT Press, Cambridge, Mass.

[2] Baillie, R.T. and Selover, D.D. (1987), "Cointegration and Models of Exchange Rate Determination," International Journal of Forecasting, 3, 43-51.

[3] Baillie, R.T. and Pecchenino, R.A. (1991), "The Search for Equilibrium Relationships in International Finance: the Case of the Monetary Model," Journal of International Money and Finance, 10, 582-593.

[4] Baum, C.F., J.T. Barkoulas and M. Caglayan (2001), "Non-linear adjustment to purchasing power parity in the post-Bretton Woods era", Journal of International Money and Finance 20, 379-399.

[5] Brock, W., and Hommes, C. (1997), A Rational Route to Randomness, Econometrica, 65, 1059-1095

[6] Brock, W., and Hommes, C.(1998), Heterogeneous beliefs and routes to chaos in a simple asset pricing model, Journal of Economic Dynamics and Control, 22, 1235-1274.

[7] Clarida R.H., Sarno L., Taylor M. and Valente G. (2001), "The Out-OfSample Success of Term Structure Models as Exchange Rate Predictors: A Step Beyond", NBER working paper series, No.8601.

[8] De Grauwe P. and M. Grimaldi (2005): "The Exchange Rate in a Behavioural Finance Framework", Princeton University Press.

[9] De Grauwe P. And Vansteenkiste I.(2001), "Exchange Rates And Fundamentals: A Non-Linear Relationship?", Cesifo Working Paper No. 577.

[10] Diebold, F.X., Nason, J.A. (1990), "Nonparametric exchange rate prediction?", Journal of International Economics 28, 315-332.

[11] Diebold, F. X., and R. S. Mariano (1995), "Comparing Predictive Accuracy", Journal of Business and Economic Statistics, 13(3), 253-263.

[12] Eitrheim Â. and Terasvirta T., 1996, "Testing the adequacy of smooth transition autoregressive models", Journal of Econometrics, 74, 59-75.

[13] Engel, C. (1994), "Can the Markov Switching Model Forecast Exchange Rates?", Journal of International Economics, 36, 151-165.

[14] Engel, C., Hamilton, J.D. (1990), "Long swings in the dollar: are they in the data and do markets know it?", American Economic Review 80, 689-713. 
[15] Engel, C. and West, K. (2004a), "Exchange Rates and Fundamentals" NBER Working Paper 10723.

[16] Engel, C. and West, K. (2004b), "Accounting for Exchange Rate Variability in Present Value Models when the Discount Factor is Near One", American Economic Review, (Papers and Proceedings) 94, pp. 118-125.

[17] Fagan, G., Henry, J. and Mestre, R. (2001) , "An Area-Wide Model (AWM) for the Euro Area", ECB Working Paper n.42

[18] Faust J., Rogers J. H. and Wright J. H. (2003), "Exchange rate forecasting: the errors we've really made", Journal of International Economics, vol.60, pp.35-59

[19] Frankel, J. A, and A. K. Rose (1995), "Empirical Research on Nominal Exchange Rates", in: Grossman, G. and Rogoff, K., Handbook of International Economics, Vol. III, Amsterdam: Elsevier-North Holland.

[20] Frömmel, M., MacDonald, R., Menkhoff, L., (2005), Markov switching regimes in a monetary exchange rate model, Economic Modelling, 22, 485-502.

[21] Granger C.W.J. and Terasvirta T. (1993), "Modelling Nonlinear Economic Relationships", Oxford University Press.

[22] Groen, J. (2000), "The Monetary Exchange Rate Model as a Long-Run Phenomenon," Journal of International Economics, 52, 299-319.

[23] Hamilton J. (1989), A New Approach to the Economic Analysis of Nonstationary Time Series and the Business Cycle, Econometrica, 57(2), pp. 357-384.

[24] Hamilton J. (1990), Analysis of Time Series Subject to Changes in Regime, Journal of Econometrics, 45, pp. 39-70.

[25] Krolzig H.-M. (1997), Markov-Switching Vector Autoregressions Modelling, Statistical Inference, and Application to Business Cycle Analysis, Springer Verlag, pp. 357.

[26] Krolzig, H.-M., and Toro, J. (1998), A new approach to the analysis of shocks and the cycle in a model of output and employment, Working paper eco 99/30, EUI, Florence.

[27] Kilian, L., Taylor, M.P. (2003), Why is it so difficult to beat the random walk forecast of exchange rates?, Journal of International Economics, $60,85-107$.

[28] James, J. (2003), Simple trend-following strategies in currency trading, Quantitative Finance, vol.3, no. 4.

[29] Johansen, S. (1988): "Statistical Analysis of Cointegration Vectors", Journal of Economic Dynamic and Control, 12, n.2, pp.231-254. 
[30] Johansen, S. (1991), Estimation and hypothesis testing of cointegrated vectors in Gaussian vector autoregressive models, Econometrica, 59, pp.1551-1580

[31] Kirman, A. (1993), Ants, rationality and recruitment, Quarterly Journal of Economics, 108: 137-156.

[32] la Cour, L. and R. MacDonald (2000), Modelling the ECU Against the US Dollar: A Structural Monetary Interpretation, Journal of Business E Economic Statistics 18, 436-450.

[33] Lux T., and Marchesi, M., (1999), Scaling and Criticality in a Stochastic Multi-Agent Model of a Financial Market, Nature, 397, 498-500.

[34] Luukkonen R., Saikkonen P. and Terasvirta T. (1988), "Testing linearity against smooth transition autoregressive models", Biometrika 75, 491-499.

[35] Luukkonen R. and Terasvirta T. (1991), "Testing linearity of economic time series against smooth cyclical asymmetry", Annales d'Economie et de Statistiques 20/21, 125-142.

[36] Mark N., (1995), Exchange rates and fundamentals: evidence on longhorizon predictability, American Economic Review, 85, 201-218.

[37] Mark N. and D. Sul (2001): Nominal Exchange Rates and Monetary Fundamentals: Evidence from a Small Post-Bretton Woods Panel, Journal of International Economics, 53, pp.29-52.

[38] Meese, R. A. (1990), "Currency Fluctuations in the Post-Bretton Woods Era", Journal of Economic Perspectives 4, 117-134.

[39] Meese R. A. and K. Rogoff (1983). Empirical Exchange Rate Models of the Seventies: Do They Fit Out of Sample?, Journal of International Economics, 14(1-2), pp. 3-24.

[40] Meese, R.A., Rose, A.K. (1990), Nonlinear, nonparametric, nonessential exchange rate estimation, American Economic Review 80, 192-196.

[41] Meese, R.A., Rose, A.K. (1991), An empirical assessment of nonlinearities in models of exchange rate determination, Review of Economic Studies 58, 603-619.

[42] McNown, R.A., Wallace, M. (1994), "Cointegration tests of the monetary exchange rate model for three high inflation economies", Journal of Money Credit and Banking 26 (3-1), pp.396-411.

[43] Michael, P., A. R. Nobay \& D. A. Peel (1997), "Transactions Costs and Nonlinear Adjustment in Real Exchange Rates: An Empirical Investigation," Journal of Political Economy, 105, pp. 862-879. 
[44] Neely, C.J. and Sarno, L. (2002), "How Well Do Monetary Fundamentals Forecast Exchange Rates?", Federal Reserve Bank of St. Louis Review, 84, pp. 51-74.

[45] Obstfeld, M. and Rogoff, K. (1996), Foundations of International Macroeconomics, MIT Press, Cambridge, Mass.

[46] Obstfeld, M. and Rogoff, K. (2001): "The Six Major Puzzles in International Macroeconomics: Is There a Common Cause?" in B.S Bernanke, and K. Rogoff (eds.), NBER Macroeconomics Annual 2000, MIT Press 339-390.

[47] Sarantis, N., (1999), "Modeling non-linearities in real effective exchange rates", Journal of International Money and Finance, 18, 27-45.

[48] Rapach D.E. and Wohar M.E. (2002), "Testing the Monetary Model of Exchange Rate Determination: New Evidence from a Century of Data", Journal of International Economics, vol. 58(2), pp.359-385.

[49] Sarno L., (2000), "Real exchange rate behaviour in the Middle East: a re-examination", Economics Letters 66, 127-136.

[50] Sarno L., Valente G. And Wohar M. E.(2003), "Monetary Fundamentals And Exchange Rate Dynamics Under Different Nominal Regimes", CEPR Discussion Papers No.3983.

[51] Taylor M. and Peel D. (2000): "Nonlinear adjustment, long-run equilibrium and exchange rate fundamentals", Journal of International Money and Finance, 19, pp. 33-53

[52] Taylor M., Peel D. and Sarno L. (2001): "Nonlinear Mean-Reversion in Real Exchange rate: towards a Solution to the Purchasing Power Parity", International Economic Review, 42(4), pp.1015-42

[53] Terasvirta T. and Anderson H.M. (1992), "Characterizing nonlinearities in business cycles using smooth transition autoregressive models", Journal of Applied Econometrics, 7, S119-S136.

[54] van Dijk D. and P.H. Franses, (1999), "Modeling multiple regimes in the business cycle", Macroeconomic Dynamics, 3, 311-340. 


\section{CESifo Working Paper Series}

(for full list see www.cesifo-group.de)

1497 Panos Hatzipanayotou and Michael S. Michael, Migration, Tied Foreign Aid and the Welfare State, July 2005

1498 Agata Antkiewicz and John Whalley, BRICSAM and the Non-WTO, July 2005

1499 Petr Hedbávný, Ondřej Schneider and Jan Zápal, A Fiscal Rule that has Teeth: A Suggestion for a 'Fiscal Sustainability Council' underpinned by the Financial Markets, July 2005

1500 J. Atsu Amegashie and Marco Runkel, Sabotaging Potential Rivals, July 2005

1501 Heikki Oksanen, Actuarial Neutrality across Generations Applied to Public Pensions under Population Ageing: Effects on Government Finances and National Saving, July 2005

1502 Xenia Matschke, Costly Revenue-Raising and the Case for Favoring Import-Competing Industries, July 2005

1503 Horst Raff and Nicolas Schmitt, Why Parallel Trade may Raise Producers Profits, July 2005

1504 Alberto Bisin and Piero Gottardi, Efficient Competitive Equilibria with Adverse Selection, July 2005

1505 Peter A. Zadrozny, Necessary and Sufficient Restrictions for Existence of a Unique Fourth Moment of a Univariate GARCH(p,q) Process, July 2005

1506 Rainer Niemann and Corinna Treisch, Group Taxation, Asymmetric Taxation and Cross-Border Investment Incentives in Austria, July 2005

1507 Thomas Christiaans, Thomas Eichner and Ruediger Pethig, Optimal Pest Control in Agriculture, July 2005

1508 Biswa N. Bhattacharyay and Prabir De, Promotion of Trade and Investments between China and India: The Case of Southwest China and East and Northeast India, July 2005

1509 Jean Hindriks and Ben Lockwood, Decentralization and Electoral Accountability: Incentives, Separation, and Voter Welfare, July 2005

1510 Michelle R. Garfinkel, Stergios Skaperdas and Constantinos Syropoulos, Globalization and Domestic Conflict, July 2005

1511 Jesús Crespo-Cuaresma, Balázs Égert and Ronald MacDonald, Non-Linear Exchange Rate Dynamics in Target Zones: A Bumpy Road towards a Honeymoon - Some Evidence from the ERM, ERM2 and Selected New EU Member States, July 2005 
1512 David S. Evans and Michael Salinger, Curing Sinus Headaches and Tying Law: An Empirical Analysis of Bundling Decongestants and Pain Relievers, August 2005

1513 Christian Keuschnigg and Martin D. Dietz, A Growth Oriented Dual Income Tax, July 2005

1514 Fahad Khalil, David Martimort and Bruno Parigi, Monitoring a Common Agent: Implications for Financial Contracting, August 2005

1515 Volker Grossmann and Panu Poutvaara, Pareto-Improving Bequest Taxation, August 2005

1516 Lars P. Feld and Emmanuelle Reulier, Strategic Tax Competition in Switzerland: Evidence from a Panel of the Swiss Cantons, August 2005

1517 Kira Boerner and Silke Uebelmesser, Migration and the Welfare State: The Economic Power of the Non-Voter?, August 2005

1518 Gabriela Schütz, Heinrich W. Ursprung and Ludger Wößmann, Education Policy and Equality of Opportunity, August 2005

1519 David S. Evans and Michael A. Salinger, Curing Sinus Headaches and Tying Law: An Empirical Analysis of Bundling Decongestants and Pain Relievers, August 2005

1520 Michel Beine, Paul De Grauwe and Marianna Grimaldi, The Impact of FX Central Bank Intervention in a Noise Trading Framework, August 2005

1521 Volker Meier and Matthias Wrede, Pension, Fertility, and Education, August 2005

1522 Saku Aura and Thomas Davidoff, Optimal Commodity Taxation when Land and Structures must be Taxed at the Same Rate, August 2005

1523 Andreas Haufler and Søren Bo Nielsen, Merger Policy to Promote 'Global Players'? A Simple Model, August 2005

1524 Frederick van der Ploeg, The Making of Cultural Policy: A European Perspective, August 2005

1525 Alexander Kemnitz, Can Immigrant Employment Alleviate the Demographic Burden? The Role of Union Centralization, August 2005

1526 Baoline Chen and Peter A. Zadrozny, Estimated U.S. Manufacturing Production Capital and Technology Based on an Estimated Dynamic Economic Model, August 2005

1527 Marcel Gérard, Multijurisdictional Firms and Governments' Strategies under Alternative Tax Designs, August 2005

1528 Joerg Breitscheidel and Hans Gersbach, Self-Financing Environmental Mechanisms, August 2005 
1529 Giorgio Fazio, Ronald MacDonald and Jacques Mélitz, Trade Costs, Trade Balances and Current Accounts: An Application of Gravity to Multilateral Trade, August 2005

1530 Thomas Christiaans, Thomas Eichner and Ruediger Pethig, A Micro-Level 'Consumer Approach' to Species Population Dynamics, August 2005

1531 Samuel Hanson, M. Hashem Pesaran and Til Schuermann, Firm Heterogeneity and Credit Risk Diversification, August 2005

1532 Mark Mink and Jakob de Haan, Has the Stability and Growth Pact Impeded Political Budget Cycles in the European Union?, September 2005

1533 Roberta Colavecchio, Declan Curran and Michael Funke, Drifting Together or Falling Apart? The Empirics of Regional Economic Growth in Post-Unification Germany, September 2005

1534 Kai A. Konrad and Stergios Skaperdas, Succession Rules and Leadership Rents, September 2005

1535 Robert Dur and Amihai Glazer, The Desire for Impact, September 2005

1536 Wolfgang Buchholz and Wolfgang Peters, Justifying the Lindahl Solution as an Outcome of Fair Cooperation, September 2005

1537 Pieter A. Gautier, Coen N. Teulings and Aico van Vuuren, On-the-Job Search and Sorting, September 2005

1538 Leif Danziger, Output Effects of Inflation with Fixed Price- and Quantity-Adjustment Costs, September 2005

1539 Gerhard Glomm, Juergen Jung, Changmin Lee and Chung Tran, Public Pensions and Capital Accumulation: The Case of Brazil, September 2005

1540 Yvonne Adema, Lex Meijdam and Harrie A. A. Verbon, The International Spillover Effects of Pension Reform, September 2005

1541 Richard Disney, Household Saving Rates and the Design of Social Security Programmes: Evidence from a Country Panel, September 2005

1542 David Dorn and Alfonso Sousa-Poza, Early Retirement: Free Choice or Forced Decision?, September 2005

1543 Clara Graziano and Annalisa Luporini, Ownership Concentration, Monitoring and Optimal Board Structure, September 2005

1544 Panu Poutvaara, Social Security Incentives, Human Capital Investment and Mobility of Labor, September 2005

1545 Kjell Erik Lommerud, Frode Meland and Odd Rune Straume, Can Deunionization Lead to International Outsourcing?, September 2005 
1546 Robert Inklaar, Richard Jong-A-Pin and Jakob de Haan, Trade and Business Cycle Synchronization in OECD Countries: A Re-examination, September 2005

1547 Randall K. Filer and Marjorie Honig, Endogenous Pensions and Retirement Behavior, September 2005

1548 M. Hashem Pesaran, Til Schuermann and Bjoern-Jakob Treutler, Global Business Cycles and Credit Risk, September 2005

1549 Ruediger Pethig, Nonlinear Production, Abatement, Pollution and Materials Balance Reconsidered, September 2005

1550 Antonis Adam and Thomas Moutos, Turkish Delight for Some, Cold Turkey for Others?: The Effects of the EU-Turkey Customs Union, September 2005

1551 Peter Birch Sørensen, Dual Income Taxation: Why and how?, September 2005

1552 Kurt R. Brekke, Robert Nuscheler and Odd Rune Straume, Gatekeeping in Health Care, September 2005

1553 Maarten Bosker, Steven Brakman, Harry Garretsen and Marc Schramm, Looking for Multiple Equilibria when Geography Matters: German City Growth and the WWII Shock, September 2005

1554 Paul W. J. de Bijl, Structural Separation and Access in Telecommunications Markets, September 2005

1555 Ueli Grob and Stefan C. Wolter, Demographic Change and Public Education Spending: A Conflict between Young and Old?, October 2005

1556 Alberto Alesina and Guido Tabellini, Why is Fiscal Policy often Procyclical?, October 2005

1557 Piotr Wdowinski, Financial Markets and Economic Growth in Poland: Simulations with an Econometric Model, October 2005

1558 Peter Egger, Mario Larch, Michael Pfaffermayr and Janette Walde, Small Sample Properties of Maximum Likelihood Versus Generalized Method of Moments Based Tests for Spatially Autocorrelated Errors, October 2005

1559 Marie-Laure Breuillé and Robert J. Gary-Bobo, Sharing Budgetary Austerity under Free Mobility and Asymmetric Information: An Optimal Regulation Approach to Fiscal Federalism, October 2005

1560 Robert Dur and Amihai Glazer, Subsidizing Enjoyable Education, October 2005

1561 Carlo Altavilla and Paul De Grauwe, Non-Linearities in the Relation between the Exchange Rate and its Fundamentals, October 2005 